\title{
Time Context of Cue-Outcome Associations Represented by Neurons in Perirhinal Cortex
}

\author{
(DManoj Kumar Eradath, ${ }^{1,2}$ Tsuguo Mogami, ${ }^{1}$ Gang Wang, ${ }^{1,3}$ and Keiji Tanaka ${ }^{1}$ \\ ${ }^{1}$ Cognitive Brain Mapping Laboratory, RIKEN Brain Science Institute, Saitama 351-0198, Japan, ${ }^{2}$ Graduate School for Science and Engineering, Saitama \\ University, Saitama 338-8570, Japan, and 3 Department of Bioengineering, Faculty of Engineering, Kagoshima University, Kagoshima 890-0065, Japan
}

\begin{abstract}
The perirhinal cortex (PRh), which has extensive connections with diverse brain sites, may contribute to semantic memory by associating various types of information about objects. However, the extent of the types of associations in which PRh participates is unknown. In the present study, we let monkeys experience a consistent contingency between visual cues and different types of outcomes (water reward and sound-only acknowledgment) in a particular time context for many days and then recorded neuronal activities from PRh and area TE, which is the major source of visual inputs to PRh. We found that PRh cells represented the outcome type in their responses to the visual cues only in the time context in which the monkeys had experienced the cue-outcome contingency. In contrast, TE cells represented the outcome information whenever the cue appeared (i.e., independently from the related time context). These results showed that $\mathrm{PRh}$ cells represented not only the cue-outcome contingency but also the time context in which the monkeys had experienced the contingency. We conclude that PRh is not specific to the representation of sensory and associative properties of objects themselves but may represent broader information about objects, including the time context in which the objects are associated with particular outcomes.
\end{abstract}

Key words: area TE; inferotemporal cortex; macaque monkey; reward

\section{Introduction}

The perirhinal cortex (PRh) is a polymodal area that has reciprocal connections with later cortical stages of various sensory modalities as well as the orbitofrontal cortex, amygdala, and entorhinal cortex (ERh) (Suzuki and Naya, 2014) and receives dopaminergic projection from the ventral tegmental area (Goldsmith and Joyce, 1996; Wise, 2004). There is a considerable amount of evidence in macaque monkeys showing that PRh is involved in associations of various types of information about objects. Cells in macaque PRh respond to both of paired visual stimuli that the monkey has learned to associate with each other (Miyashita and Chang, 1988; Sakai and Miyashita, 1991; Higuchi and Miyashita, 1996; Erickson and Desimone, 1999; Messinger et al., 2001). Furthermore, monkeys with lesions in PRh have difficulty in learning the visual paired association (Buckley and Gaffan, 1998). Combined lesions of PRh and ERh also produce deficits in visual-taste (Parker and Gaffan, 1998) and visual-

Received Nov. 18, 2014; revised Jan. 8, 2015; accepted Jan. 28, 2015.

Author contributions: M.K.E., T.M., and K.T. designed research; M.K.E., T.M., and K.T. performed research; G.W. contributed unpublished reagents/analytic tools; M.K.E., T.M., and K.T. analyzed data; M.K.E. and K.T. wrote the paper.

This work was supported in part by the Japan Society for the Promotion of Science through the Funding Program for World-Leading Innovative R\&D on Science and Technology (FIRST Program). We thank Sidney Lehky for improving the English of the manuscript.

The authors declare no competing financial interests.

This article is freely available online through the J Neurosci Author Open Choice option.

Correspondence should be addressed to Dr. Keiji Tanaka, Cognitive Brain Mapping Laboratory, RIKEN Brain Science Institute, Wako-shi, Saitama 351-0198, Japan. E-mail: keiji@riken.jp.

DOI:10.1523/JNEUROSCI.4730-14.2015

Copyright $\odot 2015$ the authors $\quad 0270-6474 / 15 / 354350-16 \$ 15.00 / 0$ tactile associative learning (Goulet and Murray, 2001). Not only associations between sensory stimuli, but also associations between visual stimuli and reward-related events are represented in PRh. PRh cells, in their responses to associated visual cues, represent the position of a current trial in reward schedules or forthcoming outcome types (Liu and Richmond, 2000; Mogami and Tanaka, 2006; Ohyama et al., 2012). Combined lesions of PRh and ERh or suppression of D2 dopamine receptors in PRh and ERh reduce the dependence of monkeys' behavior on the association between visual cues and positions in reward schedules (Liu et al., 2000, 2004). Associations of various types of information about objects may be the core of semantic memory (McClelland and Rogers, 2003), and PRh may contribute to the semantic memory by associating various types of information about objects. Involvement of PRh in semantic memory has also been suggested in humans (Davies et al., 2004; Taylor et al., 2006; Holdstock et al., 2009; Wang et al., 2010; Chan et al., 2011).

Several groups of authors have commonly proposed that the information of objects, or items, conveyed by PRh is integrated in the hippocampus with the information of contexts, especially that of spatial contexts, conveyed by the parahippocampal areas (Davachi, 2006; Eichenbaum et al., 2007; Pascalis et al., 2009; Ranganath and Ritchey, 2012). According to these ideas, associations that occur in PRh are limited to those for objects or items. Therefore, it is important to determine the extent of the types of associations that occur in PRh. The present study focused on the time context of cue-outcome associations and aimed at determining whether it is represented by activities in PRh cells. We compared activities in PRh with those in area TE (Tanaka, 1996), which is the main source of visual inputs to PRh. We expected the 


\section{Associated with water reward}

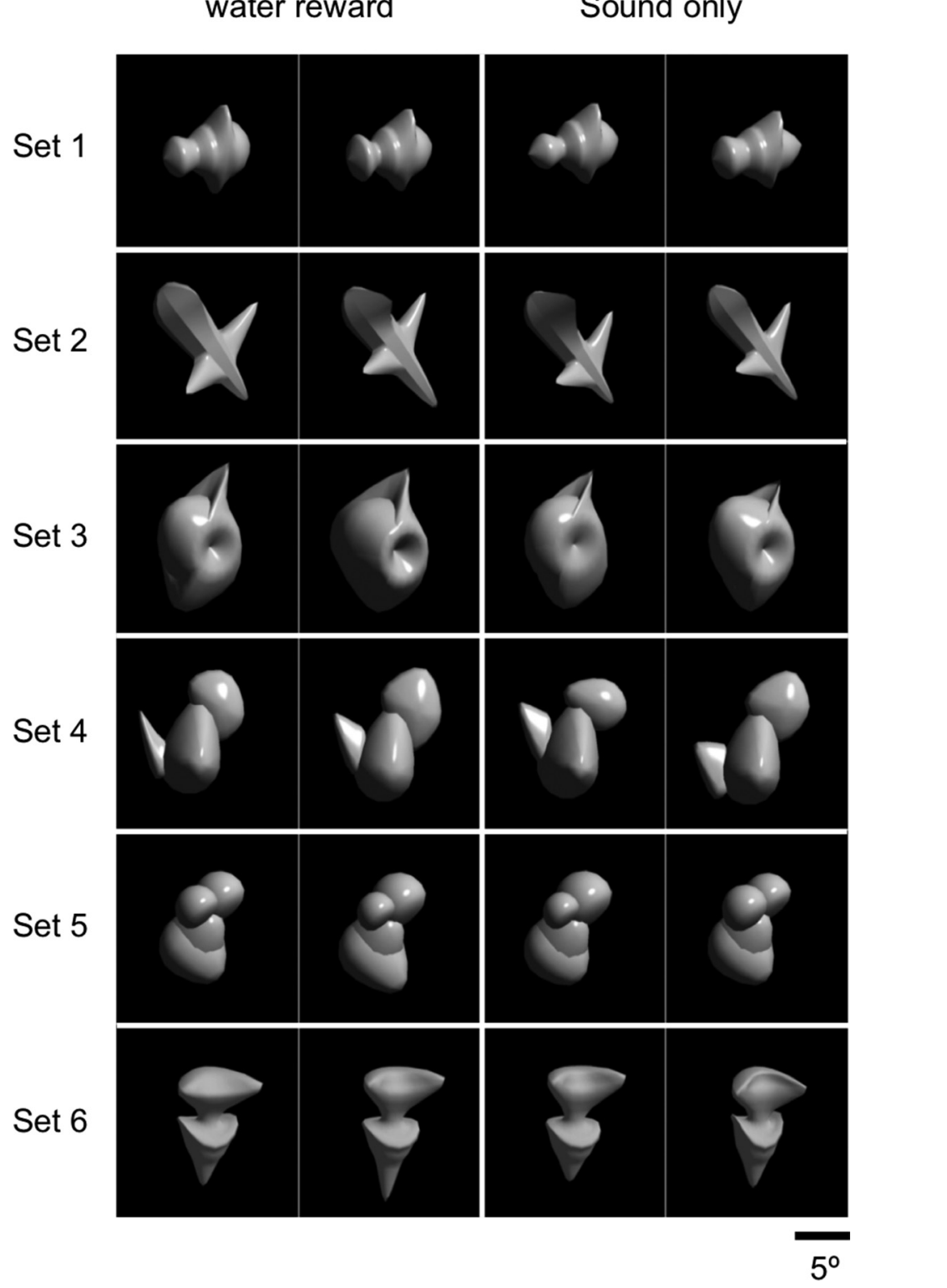

\section{Associated with Sound only}

Stimuli. We used images of computergenerated meaningless objects as visual stimuli (Fig. 1). The stimuli were created in the same way as those in our previous study (Wang et al., 2005). There were 6 sets of stimuli, each of which consisted of 4 stimuli (together 24 stimuli). The 4 stimuli in each set were created by deforming a parent stimulus of the set in four different directions in a feature space. Human psychophysics was used to make the subjective similarity between any stimulus pair comparable within each set and to make the subjective similarity within each set comparable between sets. Differences between sets were much larger than differences within each set.

Experiments with fixed cue-outcome contingency. The monkeys conducted a task that required both continuous lever-pressing and continuous eye-fixation while a visual cue was presented. The cue indicated the outcome type that would occur at the end of trial if leverpressing and eye-fixation were maintained. The monkey sat in a chair, with the head fixed to the chair by the titanium bar implanted to the skull, facing a cathode ray tube display placed $50 \mathrm{~cm}$ from the monkey's eyes. A lever was placed in front of the monkey's body. The monkey pressed the lever to start a trial. A fixation point (a white square subtending $0.7^{\circ}$ of visual angle) immediately appeared at the center of the display. The monkey had to fixate eye gaze within $\pm 2.5^{\circ}$ from the fixation point within $500 \mathrm{~ms}$. When the monkey had continued the lever-pressing and eye-fixation for 400 $\mathrm{ms}$, the fixation point was replaced with a visual cue. The cue was pseudo-randomly selected from the 24 stimuli with a constraint that two stimuli from the same set never appeared consecutively. The visual cue was presented for $350 \mathrm{~ms}$, and the fixation point reappeared after that. The fixation window was set relatively large to realize a good success rate in unrewarded trials.

Twelve of the 24 stimuli (two in each set) were consistently associated with water reward and the other 12 stimuli (two other stimuli in each set) with no reward (Fig. 1). In trials in which the visual cue was one of those associated with reward ("reward-associated cues," $\mathrm{R})$, the continued lever-pressing and eyefixation was rewarded with a drop of water twice: first at $600 \mathrm{~ms}$ and second at $1000 \mathrm{~ms}$ after the visual cue onset (see Fig. $3 A$ ). The

Visual stimuli used in the experiments. The 24 stimuli consisted of 6 sets of 4 stimuli. The stimuli were associa the two outcome types as noted at the top for Monkey 1. The stimuli in the first and third columns from the left were associated with the water reward and those in the second and forth columns with the sound-only acknowledgment for Monkey 2. Differences within each set were much smaller than differences between sets.

comparison with TE to reveal unique functions that emerge at the stage of PRh. We let monkeys experience a consistent contingency between visual cues and different types of outcomes (water reward and sound-only acknowledgment) in a particular time context for many days and then recorded neuronal activities from PRh and TE.

\section{Materials and Methods}

Subjects. Two male macaque monkeys (Macaca mulatta) were used. All experiments were approved by the RIKEN Animal Experiment Committee, and all procedures were performed in accordance with the guidelines of the Japan Neuroscience Society. A titanium head-fixating bar and a titanium recording chamber were implanted with titanium screws and dental acrylic onto the dorsal aspect of the skull in aseptic surgeries under general anesthesia with isoflurane $(1.0 \%-2.0 \%)$. monkey had to keep the lever-pressing and eye-fixation until the second reward onset. In trials in which the cue was one of those associated with no reward ("no-reward-associated cues," NR), the successful continuation of lever-pressing and eye-fixation was acknowledged only by a click sound identical to that associated with the water reward delivery. The click sound was provided twice at the timings at which the reward would have been delivered if the trial had been a rewarded trial. The monkey had to continue lever-pressing and eye-fixation until the second click sound even during unrewarded trials to move to the next trial, which was possibly rewarded. There was a $200 \mathrm{~ms}$ intertrial interval (ITI) after the onset of the second outcome before the monkey could start the next trial. When the monkey broke the lever-pressing or eye-fixation during a trial, the trial was immediately terminated and a longer $(700 \mathrm{~ms})$ ITI was initiated. An unsuccessful trial was followed by a trial with the same visual cue. Each of the monkeys performed 900-1000 trials per daily session. 
The monkeys were first trained for the leverpressing and eye-fixation with visual stimuli different from those used in the main experiments, and then the 24 stimuli were introduced at once. Neuronal recordings started after the proportion of trials with successful performance of continuous lever-pressing and eyefixation (success rate, sr) or the pressure to suck the reward-delivery tube before the onset of reward delivery (anticipatory sucking pressure, $\mathrm{sp}$ ) showed clear dependence (see Analyses of monkey behavior) on the outcome type associated with the cue (water reward vs sound-only acknowledgment), indicating that the monkey had learned the cue-outcome contingency. The eye position was monitored with an infrared pupil position monitoring system (i-rec; http://staff.aist.go.jp/k.matsuda/eye/ indexe.html).

No-cue rewarded trials ( $n c R)$. After a part of recordings was completed, we introduced an additional type of trials, which were identical to ordinary rewarded trials, except that visual cues were not presented. The fixation point disappeared during the $350 \mathrm{~ms}$ period in which a visual cue was presented in the ordinary trials. No-cue rewarded trials were provided with a probability of 1 of 14 .

Experiments with context-dependent cue-outcome contingency. After cell recordings with the task having fixed cue-outcome contingency were completed, the trial structure was changed so that the cue-outcome contingency depended on the time context. A visual cue presentation and outcome delivery sequence was repeated twice during a continuous lever-pressing and eye-fixation period in each trial (see Fig. 6A). In the first part of the trial, there was a fixed contingency between visual cues and the outcome type that occurred following successful task performance (continuous lever-pressing and eye-fixation). This part of the trial was the same as the previous task with a single cue-outcome sequence in each trial. In particular, the mapping between visual cues and outcome types remained the same as that in that previous task. The cue-outcome mapping was constant throughout all the experiments described in this paper. In the second part of the trial, there was no fixed contingency between the visual cues and outcome types. A water reward was randomly provided to successful performance in $50 \%$ of trials, and only a click sound was provided to successful task performance in the remaining trials.

As in trials with fixed cue-reward contingency, the monkey pressed the lever to start a trial, and then the fixation point appeared. After continuous lever-pressing and eye-fixation for $400 \mathrm{~ms}$, a visual cue was presented for $350 \mathrm{~ms}$, and an outcome was provided $600 \mathrm{~ms}$ after the first cue onset. After a delay of $800 \mathrm{~ms}$ starting at the onset of the outcome in the first part, another visual cue was presented for $350 \mathrm{~ms}$ and an outcome was provided $600 \mathrm{~ms}$ after the second cue onset. We refer to the first part of trial as "contingent part" and the second part as "noncontingent part." The overall frequency of water reward delivery was identical between the two parts. The monkey had to keep the lever pressed and eye fixed throughout the trial $(2800 \mathrm{~ms})$, including both the first and second parts. The fixation spot remained at the center of the screen, except during the cue presentation periods. The stimulus used as a cue in the second part of a trial was always different from that presented in the first part of the trial. A successful trial was followed by an ITI of $800 \mathrm{~ms}$. When the monkey broke eye-fixation or released the lever during a trial, the trial was immediately terminated and a longer ITI of $1000 \mathrm{~ms}$ started. An unsuccessful trial was followed by a trial in which the last stimulus associated with the error was presented again as the first cue. Each of the monkeys performed 600-800 trails in each daily session.

We refer to the cues that were associated with the reward and no reward in the contingent part of trails as "reward-associated cues" and "no-reward-associated cues," respectively. We use these terms even in descriptions of the monkeys' behavior and cell activities in the noncon- tingent part of the trial, for the sake of convenience. Cell recordings started after the monkey showed clear evidence either in success rate or in anticipatory sucking that it had learned the context dependence of cueoutcome contingency.

Switches of the context for cue-outcome contingency. After conducting cell recordings for 18 weeks for Monkey 1 and 16 weeks for Monkey 2 with the above-described order of the contingent and noncontingent parts in each trial (the contingent part followed by the noncontingent part), the order of contingent and noncontingent parts was reversed (the "first context switch"). After this first context switch, one of the two types of outcome was randomly provided to successful performance in the first part of the trial, whereas the two outcome types were given on contingency to visual cues in the second part of the trial. After a second series of cell recordings for 20 weeks for Monkey 1 and 17 weeks for Monkey 2, the order of contingent and noncontingent parts in a trial was returned to the original (the "second context switch"). Cell recordings were conducted for 4 weeks for Monkey 1 and 2 weeks for Monkey 2 after the second context switch. The mapping from the 24 visual cues to the 2 outcome types remained the same across the two context switches. There was no sign given to the monkeys indicating the context switches.

Cell recordings. Single-cell activities were recorded from the PRh and area TE with tungsten microelectrodes (Frederick Haer) while the monkeys were performing the behavioral tasks. Two tungsten microelectrodes were penetrated simultaneously from the dorsal surface of the brain through stainless steel guide tubes to one of the two areas, at an exactly vertical angle for perirhinal recordings and at an angle (15 degrees) tilted to the lateral (as the electrode descended ventrally) for TE recordings. Locations of the perirhinal cortex and area TE were determined from MRIs taken before the preparatory surgery. The dura positions at the ventral surface of the brain were determined for each of the recording penetrations by observing the characteristic noises that occurred when the electrode made contact with the dura. The recorded locations ranged from anterior 10 to anterior $17 \mathrm{~mm}$ with respect to the interaural line (Fig. 2). All the recordings were made from the left hemisphere. PRh and TE recordings were conducted on alternative days, except days after the second context switch in the experiments with context-dependent cue-outcome contingency. In these latter days, we focused on recordings in PRh. Spikes from a single cell were isolated by MSD (Multi Spike Detecting system, Alpha Omega). The rastergrams were monitored online for isolated spikes; and when the recorded cell did not appear to change the activity in relation to the task events, we advanced the electrode to find another cell. Cells recorded for a minimum of 100 trials were used for neuronal analyses unless otherwise noted.

Analyses of monkey behavior. We calculated the proportion of trials in which the monkey broke the lever-pressing or eye-fixation during the 
period extending from the onset of cue presentation to the onset of outcome (break rate) and then defined the success rate (sr) by 1 - break rate. We used the success rate as an indicator of the monkey's motivation to complete the trial or the trial part, which in turn indicates the monkey's level of anticipation of the water reward provided at the end of the trial or trial part.

The pressure in the water-reward delivery tube was continuously monitored by a pressure sensor. The pressure was influenced by both the water delivery and the monkey's sucking of the tube. There was an $\sim 50$ ms delay from the onset of the electrical signal to the actual supply of water to the monkey's end of the tube. We found that one of the two monkeys (Monkey 2) started to suck the tube $\sim 100$ ms before the electrical onset of reward delivery in trials in which one of the stimuli associated with water reward was presented as the cue. We measured the pressure of this anticipatory sucking as another indicator of monkey's anticipation of the water reward. The mean pressure was measured over a $150 \mathrm{~ms}$ window starting $100 \mathrm{~ms}$ before the electrical signal onset of the outcome, with subtraction of the mean baseline pressure measured over a $150 \mathrm{~ms}$ window placed immediately before the onset of visual cues (the first visual cue for trials with repeated cue-outcome sequence).

To examine the significance of the difference within each day of behavioral responses to reward-associated and no-reward-associated cues, we also calculated the success rate and anticipatory sucking separately for individual stimuli, and then averaged them across the two stimuli belonging to the same set and associated with the same outcome type. We thus obtained six pairs of success rates and anticipatory sucking pressures (note that we used six stimulus sets) following reward-associated and no-reward-associated cues. We then applied a paired $t$ test to the six pairs of success rates or anticipatory sucking pressures. All successful trials (continuous lever-pressing and eye-fixation throughout the trial) were included in the analyses of anticipatory sucking.

Analyses of cell data. Trials with successful performance (continuous lever-pressing and eye-fixation throughout the trial) were used for the analyses of cell activities, both in relation to the cue presentation and to the outcome delivery. Responses to the visual cue presentation were measured by the mean firing rate in a $500 \mathrm{~ms}$ window starting $100 \mathrm{~ms}$ after the cue presentation onset, whereas baseline activities were determined by the mean firing rate in a $400 \mathrm{~ms}$ window placed immediately before the cue onset (the first cue onset for trials with repeated cueoutcome sequences in each trial). The responsiveness of a cell to the cues was examined by two-way ANOVA with baseline/response and stimulus as factors. For cells recorded in trials with a single cue-outcome sequence, a cell was regarded as cue-responsive if it showed a significant baseline/ response main effect or significant interaction ( $p<0.025$ each). For cells recorded in trials with repeated cue-outcome sequences, responses were measured for two response windows placed in the first and second parts of the trial, and a cell was regarded as responsive if it showed a significant baseline/response main effect or significant interaction in either response window $(p<0.0125$ each $)$.

Responses to visual cues were further analyzed for their selectivity to visual properties and associated outcome types (water reward vs soundonly acknowledgment) by using a nested ANOVA. The 24 stimuli were composed of 6 stimulus sets and 2 associated outcome types (Fig. 1). The sets were crossed with the associated outcome types, and each combination of set and associated outcome type contained two stimuli. The selectivity for sets and that for associated outcome types were examined by comparing the mean SS (sum of the squared deviation from the mean) for sets or associated outcome types with the mean SS for stimuli within each combination of set and associated outcome type.

For cells recorded during a period before the first context switch in the second series of experiments, the periods in which each cell showed significantly larger activities in response to reward-associated cues and water reward delivery in the first (contingent) part of the trial were determined by examining the significance of the difference in a $200 \mathrm{~ms}$ window moving in $20 \mathrm{~ms}$ steps ( $p<0.05$, two-tailed Mann-Whitney $U$ test). The periods with significant differences were determined with respect to the center of the window. The center of the $200 \mathrm{~ms}$ window was moved from $100 \mathrm{~ms}$ after the first cue onset to the offset of the second cue. When a cell showed significant response differences in two periods
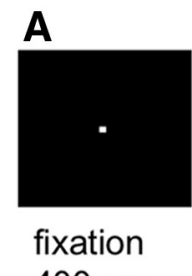

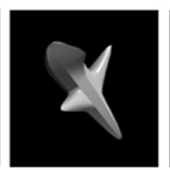

cue $350 \mathrm{~ms}$

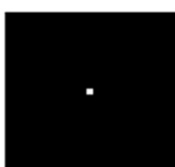

fixation $250 \mathrm{~ms}$

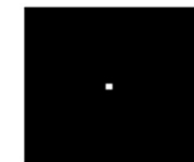

fixation $400 \mathrm{~ms}$ or $\sqrt{1))}$ (1)

B

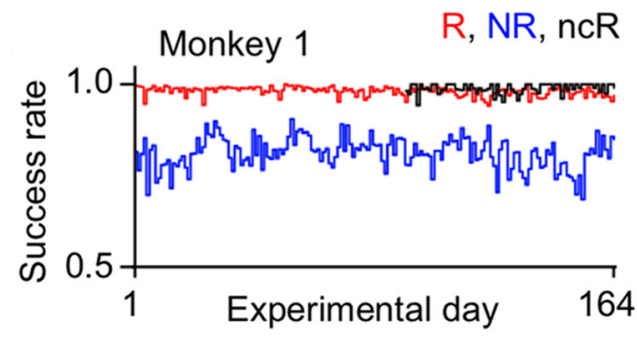

C

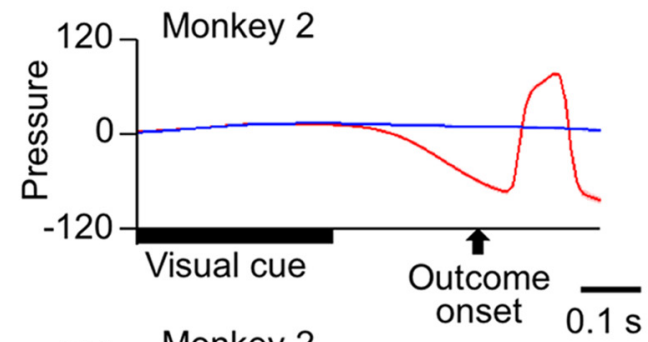

D

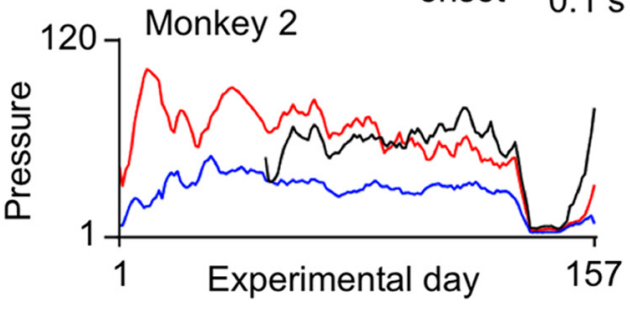

Figure 3. Trial structure and behavioral results for the experiments with fixed cue-outcome contingency. A, Events in a trial. There was one sequence of visual-cue presentation and outcome delivery in each trial. Depending on the cue, a water reward or a clicking sound was provided. The same outcome was repeated twice in each trial. Monkeys were only required to maintain lever-pressing and eye-fixation throughout the trial. $\boldsymbol{B}$, Daily calculated success rate of Monkey 1 plotted against the experimental day. $\boldsymbol{B}-\boldsymbol{D}$, Red and blue lines indicate values in rewarded $(R)$ and unrewarded trials $(N R)$, respectively. Black lines indicate values in no-cue rewarded trials (ncR). The success rate was calculated by 1 - break rate, where the break rate was the proportion of trials in which the monkey broke the lever-pressing or eye-fixation during a period from the cue onset to the first outcome onset. $\boldsymbol{C}$, The pressure within the tube for water reward delivery in Monkey 2 . The negative deflection near the first outcome onset in rewarded trials represented the monkey's anticipatory sucking, and the positive deflection that followed reflected the arrival of the water drop to the monkey end of the tube. $\boldsymbol{D}$, Daily calculated mean strength of anticipatory sucking in Monkey 2, measured over a 150 ms window starting $100 \mathrm{~ms}$ before the electrical onset of the first outcome, plotted against the experimental day.

that were each longer than $300 \mathrm{~ms}$, the overall period was determined from the beginning of the first period to the end of the second period.

Activities following the outcome onset were analyzed in a $500 \mathrm{~ms}$ window starting $200 \mathrm{~ms}$ after the electrical signal onset of the outcome. The click sound immediately followed the electrical signal, whereas the water drop arrived at the monkey's end of the water delivery tube after a delay of $\sim 50 \mathrm{~ms}$. Because the click sound was provided, following successful task performance, in both rewarded and unrewarded trials, the monkeys could discriminate the positive from negative feedback only after the water drop arrived. 


\section{Results}

\section{Experiments with fixed cue-outcome contingency}

We first examined representations of cue-outcome associations in PRh and TE cells. We let two monkeys experience a fixed contingency between visual cues and outcome types (water reward and click sound only) and then recorded activities of cells from PRh and TE during the task. Each trial had a single cueoutcome sequence in the task (Fig. 3A).

\section{Monkeys' behavior}

After the monkey had experienced the cue-outcome contingency for $35 \mathrm{~d}$ (in Monkey 1) or $27 \mathrm{~d}$ (in Monkey 2), cell recordings were conducted for $164 \mathrm{~d}$ (in Monkey 1) or $157 \mathrm{~d}$ (in Monkey 2). Clear evidence for the monkey's anticipation of outcome type was found in the success rate for Monkey 1 and in the anticipatory sucking for Monkey 2 during the period of cell recordings. The success rate was higher (in Monkey 1 ) or the anticipatory sucking was stronger (in Monkey 2) in trials in which a water reward was delivered for successful performance (continuous lever-pressing and eye-fixation) ("rewarded trials") than in trials in which a sound-only acknowledgment was provided for successful performance ("unrewarded trials") (Fig. $3 B-D$ ).

We measured the success rate for the period from cue presentation onset to the first outcome onset. Monkey 1 maintained the lever-pressing and eye-fixation almost perfectly in rewarded trials (the mean success rate averaged over the $164 \mathrm{~d}$ in which cell recordings were conducted, 0.98), whereas it frequently broke eye-fixation or lever-pressing in unrewarded trials (average success rate, 0.81 ). When a Wilcoxon signed rank test was applied to 164 pairs of daily calculated success rates in rewarded and unrewarded trials, the difference was highly significant $(p<0.00001$, two-tailed; Fig. 3B). Moreover, when the success rates in rewarded and unrewarded trials were calculated within each day separately for the six sets of stimuli and a paired $t$ test was applied to the six pairs (see Materials and Methods), the success rates in rewarded trials were significantly greater than those in unrewarded trials $(p<0.05$, one-tailed) for all $164 \mathrm{~d}$.

The success rates were more similar between rewarded and unrewarded trials in Monkey 2 (0.95 for rewarded trials and 0.91 for unrewarded trials, averaged over the $157 \mathrm{~d})$. Although the difference over the $157 \mathrm{~d}$ was significant $(p<0.00001$, two-tailed Wilcoxon signed rank test), the difference within each day was significant only in a half of the days $(p<0.05$, one-tailed paired $t$ test, 72 of $157 \mathrm{~d}$ ).

Monkey 2 showed clear anticipatory sucking in rewarded trials but not in unrewarded trials. The negative pressure in the reward delivery tube, reflecting the anticipatory sucking, started $\sim 100$ ms before the electrical signal onset of the reward delivery (Fig. 3C). The positive deflection that started $\sim 50 \mathrm{~ms}$ after the electrical signal onset of reward delivery reflected the arrival of the water drop to the monkey's end of the tube. Therefore, we measured the strength of anticipatory sucking by the mean negative deflection of pressure in a $150 \mathrm{~ms}$ window starting at $100 \mathrm{~ms}$ before the electrical onset of outcome from the baseline pressure measured in a $150 \mathrm{~ms}$ window before the cue onset. The pressure was then averaged over all successful rewarded trials or over all successful unrewarded trials within each day. The magnitudes of mean sucking pressure in rewarded trials were significantly larger than those in unrewarded trials, when a Wilcoxon signed rank test was applied to 157 pairs of daily calculated mean pressure values in rewarded and unrewarded trials $(p<0.00001$, twotailed; Fig. $3 D$ ). When a paired $t$ test was applied to the six pairs of mean pressure measurements calculated within each day for the six stimulus sets, the anticipatory sucking pressure in rewarded trials was significantly larger than that in unrewarded trials for most days (136 of $157 \mathrm{~d}$; $p<0.05$, one-tailed). Most of the remaining $21 \mathrm{~d}$ (19 of $21 \mathrm{~d}$ ) occurred around the 140th day, in which the monkey did not show anticipatory sucking either in rewarded or unrewarded trials. We removed these $21 \mathrm{~d}$ from the analyses of cell activities for Monkey 2.

\section{Cell activities}

Cell responses to the visual cue presentation were analyzed in a $500 \mathrm{~ms}$ window starting at $100 \mathrm{~ms}$ after the cue onset ("cueresponse window"). This window did not overlap the outcome onset. Approximately $60 \%$ of the tested PRh cells (224 of 371 in the two monkeys together: 119 of 203 in Monkey 1 and 105 of 168 in Monkey 2) and $\sim 80 \%$ of the tested TE cells (432 of 543: 233 of 319 in Monkey 1 and 199 of 224 in Monkey 2) significantly responded to cues: they showed either significant baseline/response main effects or significant interactions ( $p<0.025$ each, two-way ANOVA with baseline/response and stimulus as factors) ("cueresponsive cells"). These responses to visual cues were further analyzed in terms of the selectivity for outcome types associated with the cues and for visual properties of the cues. Selectivity for associated outcome types was found in both PRh and TE (Fig. $4 A, B$ ): $45 \%$ of the cue-responsive PRh cells ( 100 of 224: 68 of 119 in Monkey 1 and 32 of 105 in Monkey 2) and 22\% of the cueresponsive TE cells (96 of 432: 34 of 233 in Monkey 1 and 62 of 199 in Monkey 2) showed significant outcome-type main effects in nested ANOVA ( $p<0.05$; see the Materials and Methods). The selectivity for visual properties of stimuli was more prevalent in TE than in PRh (Fig. 4B). Significant selectivity for stimulus sets was found in $52 \%$ of the cue-responsive TE cells ( 223 of 432: 112 of 233 in Monkey 1 and 111 of 199 in Monkey 2) $(p<0.05$, stimulus set main effects in nested ANOVA), whereas the proportion in PRh (13\%, 29 of 224, 8 of 119 in Monkey 1 and 21 of 105 in Monkey 2$)$ was significantly smaller $(p<0.00001$ in either monkey, $z$ test).

Both the selectivity of cue responses for associated outcome types and for stimulus sets appeared in PRh cells with longer onset latency than in TE cells. Nested ANOVA was applied to activities of individual cells in $10 \mathrm{~ms}$ bins moving in $10 \mathrm{~ms}$ steps, and the onset latency of selectivity was determined in individual cells by the first of three consecutive bins with significant differences. Based on these calculations, the onset latency in TE cells was $137.4 \pm 4.9 \mathrm{~ms}$ (mean \pm SEM across cells) for the selectivity for stimulus sets and $195.4 \pm 12.1 \mathrm{~ms}$ for the selectivity for associated outcome types, whereas in PRh cells it was $162.5 \pm 25.5 \mathrm{~ms}$ for the selectivity for stimulus sets and $241.5 \pm 7.0 \mathrm{~ms}$ for the selectivity for associated outcome types. The selectivity for associated outcome types appeared in TE cells on average $46.1 \mathrm{~ms}$ earlier than in PRh cells.

To further compare the nature of selectivity in individual cells between PRh and TE, we calculated the ratio of the response variance due to associated outcome types to a sum of the variance due to associated outcome types and that due to visual properties in individual cells. The ratio was almost evenly distributed from 0 to 1 in PRh (with a mean of $0.50,0.63$ in Monkey 1 and 0.35 in Monkey 2), whereas values near 0 dominated in TE (with a mean of 0.20, 0.19 in Monkey 1 and 0.21 in Monkey 2) (Fig. 4C). The difference between the two distributions was highly significant $(p<0.00001$ in either monkey, two-tailed Mann-Whitney $U$ test). These results indicated that the translation of the cues from visual properties to the meanings (associated outcome types) of the cues occurred much more strongly in PRh than in TE. 

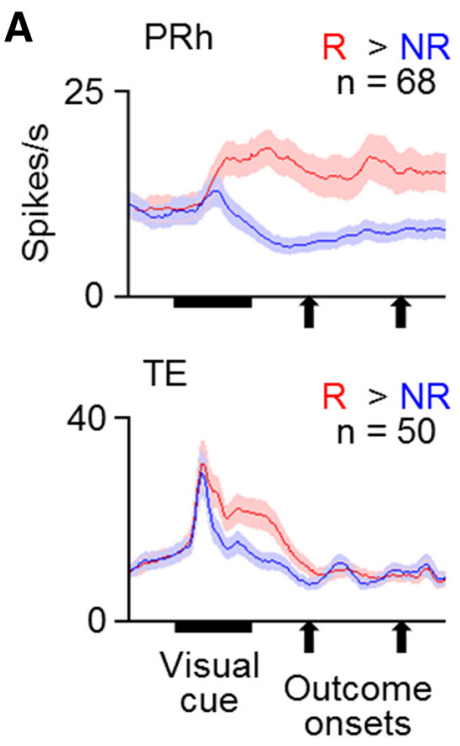

B

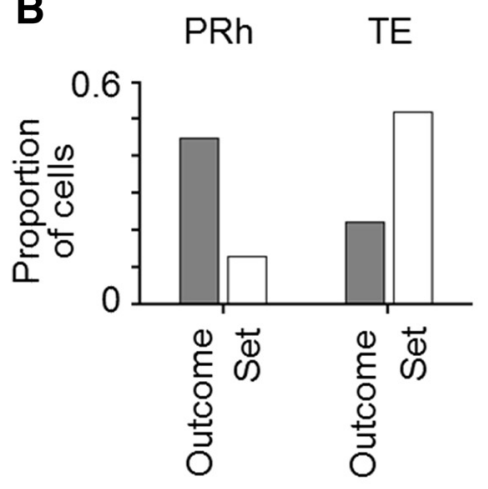

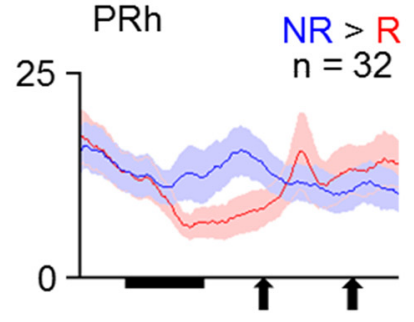
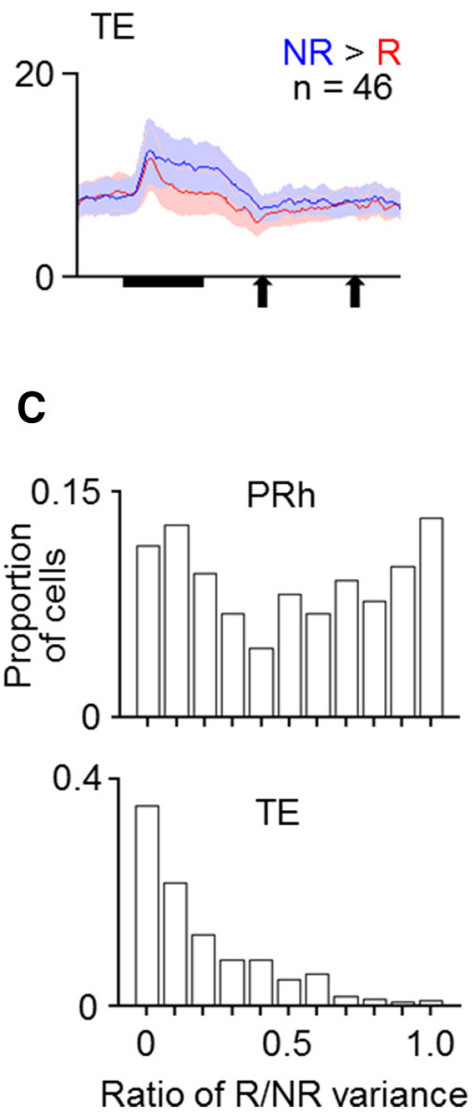

Figure 4. Responses of cells in PRh and TE to visual cues. $\boldsymbol{A}$, Mean activities averaged over cells that showed significant selectivity for associated outcome types in their cue responses. Red and blue lines indicate activities in rewarded (R) and unrewarded trials (NR), respectively. Activities were separately averaged for PRh and TE cells and for the cells with larger and smaller responses in rewarded trials than in unrewarded trials. Bin width was $10 \mathrm{~ms}$, and values were smoothened over five bins with equal weights. Shading represents SEM across cells. $\boldsymbol{B}$, Proportions of cells that showed significant selectivity for associated outcome types (Outcome) and stimulus sets (Set) in PRh and TE. C, Proportions of cells having a value within the bin range of the ratio of (the variance due to associated outcome types)/(the variance due to associated outcome types + the variance due to stimulus sets) in PRh and TE.

The selectivity of cells for the associated outcome types could not be explained by differences in the preciseness of gaze fixation between rewarded and unrewarded trials. The length of movements of gaze position per trial was calculated within the cueresponse window: the averaged gaze position was determined in $30 \mathrm{~ms}$ windows and the change of the position from the previous window to the current window was summed over the $500 \mathrm{~ms}$ window. It was generally larger in rewarded trials than in unrewarded trials. For example, in the experiments with the fixed cue-outcome contingency, it was $0.698 \pm 0.0196$ degrees (visual angle, mean \pm SEM across cells) in rewarded trials and $0.568 \pm$ 0.020 degrees in unrewarded trials during recordings from the 96 TE cells that showed significant selectivity for associated outcome types and $0.645 \pm 0.011$ degrees in rewarded trials and $0.513 \pm$ 0.011 degrees in unrewarded trials during recordings from the
$100 \mathrm{PRh}$ cells that showed significant selectivity for associated outcome types. The differences were highly significant $(p<$ 0.00001 both, two-tailed Wilcoxon signed rank test). To examine the possibility that the differences in eye movements caused the differences in cue responses between rewarded and unrewarded trials, we calculated the correlation between neuronal activities and the length of gaze movements across trials, after the means of neuronal activities and gaze movement length calculated for each stimulus were subtracted from the values in individual trials. Significant correlation in the direction that can explain the cell's selectivity for associated outcome type (positive for cells with larger activities in rewarded trials and negative for cells with smaller activities in rewarded trials) were found only in 5 of the 96 TE cells and 5 of 100 PRh cells. These proportions were not significantly larger than those expected by chance ( $p=0.18$ in TE and $p=0.18$ in $\mathrm{PRh}$, Poisson test). The differences in gaze movements could not cause the selectivity of cells for the associated outcome type.

\section{No-cue rewarded trials}

To examine whether the selectivity of cue responses for associated outcome types was a mere reflection of the monkey's expectation of outcome type or it depended on the visual inputs, we introduced trials in which no visual cue (except a disappearance of the fixation spot) was presented while the water reward was provided to successful performance ("nocue rewarded trials").

\section{Monkeys' behavior}

In Monkey 1, daily calculated success rates in no-cue rewarded trials (mean, 0.99) were significantly larger than those in unrewarded trials (mean, 0.80) when the pair of success rate was pooled over the $72 \mathrm{~d}$ in which no-cue rewarded trials were provided $(p<0.00001$, two-tailed Wilcoxon signed rank test). The success rates in no-cue rewarded trials were even significantly larger than those in ordinary rewarded trials (mean, $0.98, p<0.00001$; Fig. $3 B$ ). The success rate in unrewarded trials was also calculated separately in each day for each of the 12 stimuli. When these 12 rates were compared with the rate in no-cue rewarded trials obtained for the same day, the success rate in no-cue rewarded trials was significantly larger than those in unrewarded trials for all $72 \mathrm{~d}$ $(p<0.05$, one-tailed $t$ test $)$.

In Monkey 2, the mean pressure of anticipatory sucking averaged over no-cue rewarded trials for each day was significantly larger than that averaged over unrewarded trials $(p<0.00001$, two-tailed Wilcoxon signed rank test) and was not significantly different from that in rewarded trials $(p=0.49)$, when the comparison was pooled over the $109 \mathrm{~d}$ in which no-cue rewarded 


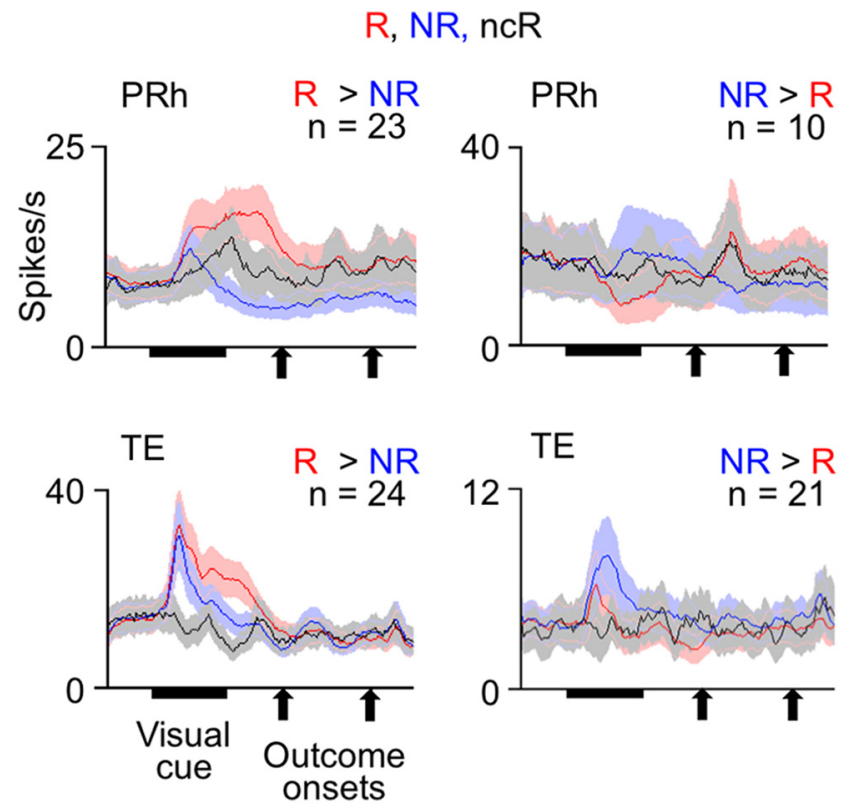

Figure 5. Mean activities of cue-responsive cells in PRh and TE in no-cue rewarded trials (ncR) compared with those in unrewarded (NR) and ordinary rewarded trials (R). Cueresponsive cells in each area were divided into two groups of cells that showed either larger or smaller responses in ordinary rewarded trials relative to unrewarded trials. Red lines indicate values in ordinary rewarded trials. Blue lines indicate values in unrewarded trials. Black lines indicate values in no-cue-rewarded trials. Bin width was $10 \mathrm{~ms}$, and values were smoothened over five bins with equal weights. Shading represents SEM across cells.

trials were provided (Fig. 3D). When the pressure in unrewarded trials was separately averaged in each day for each of 12 stimuli and those 12 values were compared with the averaged pressure in no-cue rewarded trials of the same day, the averaged pressure in no-cue rewarded trials was significantly larger than the values in unrewarded trials $(p<0.05$, one-tailed $t$ test $)$ on the sixth and all later days after the introduction of no-cue rewarded trials, but not in 4 of the 5 initial days (Fig. 3D). Therefore, we decided to exclude the initial $6 \mathrm{~d}$, in both monkeys, after the introduction of no-cue rewarded trials from the analyses of cell activities in nocue rewarded trials.

Thus, the success rate (in Monkey 1) or anticipatory sucking pressure (in Monkey 2) indicated that both monkeys anticipated the reward in no-cue rewarded trials as strongly as they did in the ordinary rewarded trials. Then, if the selectivity of cue responses had merely reflected the monkey's expectation of outcome type, activities in no-cue rewarded trials should have been identical to those in ordinary rewarded trials.

\section{Cell activities}

Cue responses of PRh and TE cells almost disappeared in no-cue rewarded trials (Fig. 5). Of 87 cue-responsive PRh cells recorded in the sessions including no-cue rewarded trials, $33 \mathrm{PRh}$ cells showed significant differences in their cue responses between unrewarded and ordinary rewarded trials $(p<0.05$, main effects of outcome type, nested ANOVA): 23 and 10 cells showed larger and smaller responses, respectively, in rewarded trials than in unrewarded trials. In both groups of cells as populations, activities in no-cue rewarded trials (1.55 \pm 1.55 spikes $/ \mathrm{s}$, mean \pm SEM across cells, for the 23 cells, $-3.26 \pm 2.75$ spikes/s for the 10 cells, after subtraction by the baseline activity) were not significantly different from zero ( $p=0.18$ for the 23 cells and $p=0.69$ for the 10 cells, two-tailed Wilcoxon signed rank test). Although the av- eraged responses of the 23 cells in no-cue rewarded trials appear to have some positive activities around the cue offset, their activities were not significantly different from zero even in 100-mslong windows $(100-200,200-300,300-400,400-500 \mathrm{~ms}$ after the cue onset) $(p>0.18$, two-tailed Wilcoxon signed rank test). In the 23 cells, the activities in no-cue rewarded trials were significantly smaller than their cue responses in ordinary rewarded trials $(6.15 \pm 1.82$ spikes/s) $(p=0.000077$, two-tailed Wilcoxon signed rank test) and larger than their activities in unrewarded trials $(-1.03 \pm 1.21$ spikes/s $)$ with a marginal significance $(p=$ 0.089 ) (Fig. 5, top left). In the other $10 \mathrm{PRh}$ cells, probably because the number of cells was small, the differences between activities in no-cue rewarded trials and those in ordinary rewarded $(-5.77 \pm 3.58$ spikes/s $)$ and unrewarded trials $(-1.02 \pm 2.99$ spikes/s) did not reach a significance level $(p=0.084$ and $p=$ 0.99, respectively) (Fig. 5, top right).

Of 162 cue-responsive TE cells recorded in the sessions including no-cue rewarded trials, 45 cells showed significant differences in their cue responses between unrewarded and ordinary rewarded trials $(p<0.05$, main effects of outcome type, nested ANOVA): 24 and 21 cells showed larger and smaller responses in rewarded trials than in unrewarded trials. In both groups of cells, activities in no-cue rewarded trials $(-1.33 \pm 0.90$ spikes/s, mean \pm SEM across cells, for the former group, $-0.13 \pm 0.26$ spikes/s, for the latter group) were not significantly different from zero $(p=0.14$ for the former group and $p=0.96$ for the latter group, two-tailed Wilcoxon signed rank test). In the former group, the activities in no-cue rewarded trials were significantly smaller than their activities in ordinary rewarded trials $(8.85 \pm$ 2.19 spikes $/ \mathrm{s})(p=0.00012$, two-tailed Wilcoxon signed rank test $)$ and unrewarded trials $(3.41 \pm 1.48$ spikes $/ \mathrm{s})(p=0.0011)$ (Fig. 5, bottom left). In the latter group, probably because the activity differences between ordinary rewarded and unrewarded trials were small, the differences between activities in no-cue rewarded trials and those in ordinary rewarded $(-0.30 \pm 0.54$ spikes/s) and unrewarded (1.38 \pm 0.69 spikes/s) trials did not reach a significance level ( $p=0.74$ and $p=0.26$, respectively) (Fig. 5, bottom right).

The dissociation between behavioral and cell results in no-cue rewarded trials suggests that the differential components of cue responses of $\mathrm{PRh}$ and TE cells selective for associated outcome types did not merely reflect the monkey's outcome anticipation or subsequent change in motivation level but depended on visual inputs.

\section{Experiments with context-dependent cue-outcome contingency}

After confirming the results that cue responses of PRh and TE cells represented the outcome types associated with the cues, we then moved to examine whether the representations depended on the context in which the monkeys had experienced the cue-outcome contingency. To answer this question, we modified the task so that the cue-outcome sequence was repeated twice in each trial (Fig. 6A). Although the outcome type (water reward or sound only) was contingent to the cue in the first part, one of the two types of outcome was randomly provided, regardless of the cue, in the second part. Thus, the consistent cue-outcome contingency appeared only in the first part of the trial ("time context" of the cue-outcome contingency). We will refer to the cues that were associated with reward and no reward in the first part of the trial as "reward-associated cues" and "no-reward-associated cues," respectively, even when they appeared in the second part of trial, for the sake of con- 
A

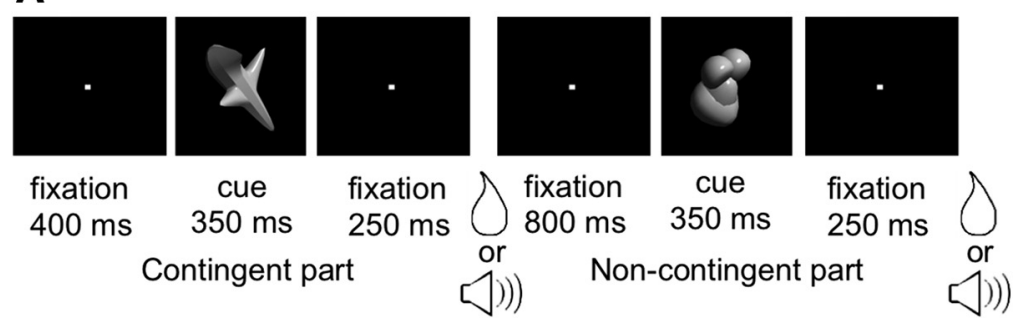

B

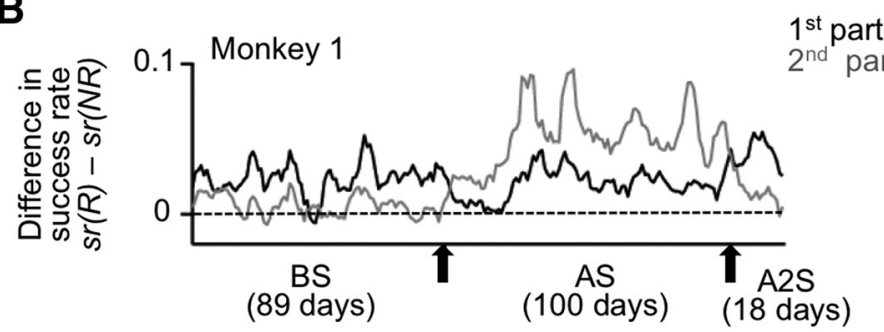

C

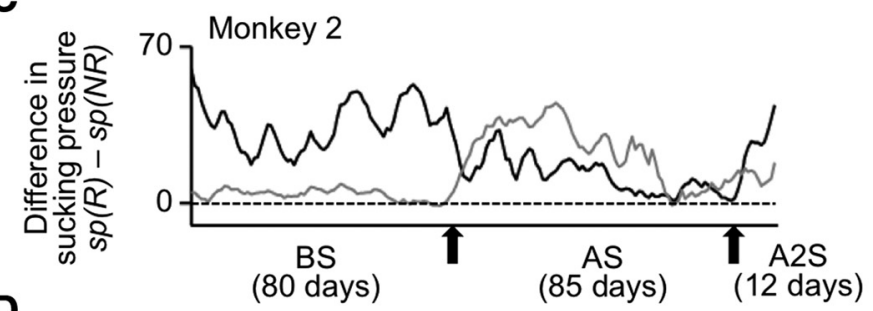

D

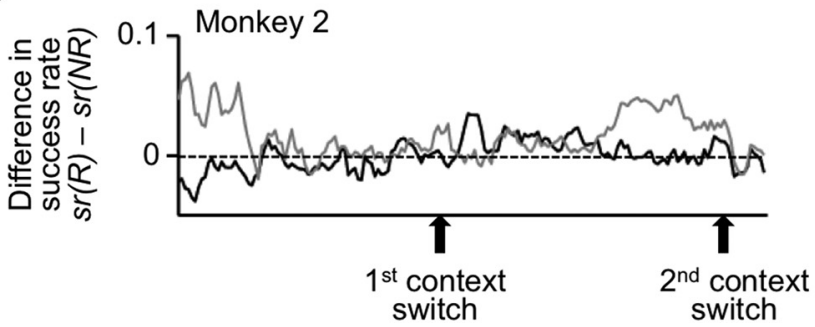

Figure 6. Trial structure and behavioral results in the experiments with context-dependent cue-outcome contingency. $\boldsymbol{A}$, Events in a trial. The sequence of a visual-cue presentation and outcome delivery was repeated twice in each trial. Before the first context switch, there was a fixed cue-outcome contingency in the first part of the trial (contingent part), whereas two types of outcome were randomly provided in the second part of the trial (noncontingent part). The order of the contingent and noncontingent parts was reversed after the first context switch and returned to the original order after the second context switch. $\boldsymbol{B}$, Difference in daily calculated success rate of Monkey 1 , after reward-associated cues minus after no-reward-associated cues, in the first and second parts of the trial. C, Difference in daily calculated mean anticipatory sucking strength of Monkey 2, after rewardassociated cues minus after no-reward associated cues, in the first and second parts of trial. $\boldsymbol{D}$, Difference in daily calculated success rate of Monkey 2, after reward-associated cues minus after no-reward associated cues, in the first and second parts of trial. $\boldsymbol{B}-\boldsymbol{D}$, Black and gray lines indicate values in the first and second parts of the trial, respectively. The values were smoothened over $5 \mathrm{~d}$ with equal weights. BS, AS, and A2S indicate the period before the first context switch, that between the first and second context switches, and that after the second context switch, respectively.

venience. The probability of rewards was identical in the first and second parts of a trial (Hammond, 1980). After experiencing the new task paradigm for $24 \mathrm{~d}$ (in Monkey 1) or $20 \mathrm{~d}$ (Monkey 2), cell recordings started. The following two sections will describe the behavioral and cellular results obtained in a period of $89 \mathrm{~d}$ (in Monkey 1) or $80 \mathrm{~d}$ (in Monkey 2) of cell recordings in this task condition.

\section{Monkeys' behavior}

Both monkeys had become adapted to the time context of cueoutcome contingency during the period of cell recordings. The monkeys' behaviors showed clear signs of anticipating the outcome type in the first part of the trial, whereas the signs were much less clear in the second part of the trial.
In Monkey 1 , the mean success rate in the first part of the trial was 0.98 and 0.96 after the presentation of reward-associated and no-reward-associated cues, respectively. When trials were sorted according to the cue presented in the second part of the trial, the success rate in the second part of the trial was 0.98 after both rewardassociated and no-reward associated cues. The success rates after reward-associated and no-reward-associated cues will be denoted as $\operatorname{sr}(R)$ and $\operatorname{sr}(N R)$, respectively, and $\operatorname{sr}(R)-s r(N R)$ in the first and second parts of the trial will be denoted as $d s r(1)$ and $d s r(2)$, respectively. When a Wilcoxon signed rank test was applied to 89 pairs of daily calculated $d s r(1)$ and $d s r(2)$, $d s r(1)$ was significantly larger than $d s r(2)$ $(p<0.00001$, two-tailed) (Fig. 6B).

To examine the significance of this difference for individual days, mean success rates after reward-associated and noreward-associated cues were calculated in each day for the six stimulus sets separately, and a paired $t$ test was applied to the six pairs of values. $d s r(1)$ was significantly larger than $d s r(2)$ in 31 of the $89 \mathrm{~d}(p<0.05$, onetailed). The differences between $d s r(1)$ and $d s r(2)$ were insignificant $(p>0.05$, onetailed) for the other $57 \mathrm{~d}$. Significant differences in the opposite direction, $d s r(2)>$ $d s r(1)$, were found in only $1 \mathrm{~d}$.

In Monkey 2, the mean anticipatory sucking pressure in the first part of the trial was 30.47 (in arbitrary units) after reward-associated cues and $\mathbf{- 5 . 1 2}$ after no-reward-associated cues, whereas the difference in the mean anticipatory sucking pressure was smaller in the second part of the trial (5.30 after rewardassociated cues and 2.91 after no-rewardassociated cues). The anticipatory sucking pressure after reward-associated and noreward-associated cues will be noted as $s p(R)$ and $s p(N R)$, respectively, and $s p(R)$ $-s p(N R)$ in the first and second parts of the trial will be noted as $d s p(1)$ and $d s p(2)$, respectively. When a Wilcoxon signed rank test was applied to 80 pairs of daily calculated $d s p(1)$ and $d s p(2), d s p(1)$ was significantly larger than $d s p(2)(p<0.00001$, two-tailed) (Fig. $6 C)$. Moreover, when the magnitudes of mean pressure of anticipatory sucking after reward-associated and after no-rewardassociated cues were calculated in each day separately for 6 stimulus sets, $d s p(1)$ was significantly larger than $d s p(2)$ for all of the $80 \mathrm{~d}$ ( $p<0.05$, one-tailed paired $t$ test).

The adaptation of the monkeys' anticipatory behavior to the time context of the cue-outcome contingency was incomplete, although strong. In Monkey 1 , whereas $d s r(2)$ was much smaller than $d s r(1), s r(R)$ in the second part of the trial was significantly larger than $\operatorname{sr}(N R)$ in that part of the trial when compared over $89 \mathrm{~d}$ ( $p=0.00069$, two-tailed Wilcoxon signed rank test). Also, in Monkey 2, whereas $d s p(2)$ was much smaller than $d s p(1), s p(R)$ in 
the second part of the trial was significantly larger than $s p(N R)$ in that part of the trial when compared over $80 \mathrm{~d}(p<$ 0.00001 , two-tailed Wilcoxon signed rank test).

\section{PRh cell activities}

The question here was whether the selectivity of cue responses for associated outcome types adapted to the time context of the cue-outcome contingency. We found different answers for PRh and TE cells. Of 113 cue-responsive PRh cells (61 in Monkey 1 and 52 in Monkey 2; 217 PRh cells were recorded in the period), 85 and 28 cells (40 and 12 in Monkey 1, 36 and 16 in Monkey 2) showed numerically larger and smaller cue responses, respectively, after reward-associated cues than after noreward-associated cues (for mean activities averaged over the first and second parts of the trial). Activities of an example of the 85 cells are shown in Figure 7, and activities averaged over the 85 cells are shown in Figure $8 A$. In these figures, the activities in the second part of the trial were sorted by the cue presented in that part of the trial, but not by the outcome type given in that part of the trial. The mean firing rates in the cue-response window after reward-associated and noreward-associated cues will be denoted as $f r(R)$ and $f r(N R)$, respectively. We normalized $f r(R)$ and $f r(N R)$ by a sum of $f r(R)$ and $f r(N R)$ over both the first and second parts of the trial (a sum of four values). The normalized $f r(R)$ and $f r(N R)$ will be referred to as $n f r(R)$ and $n f r(N R)$, respectively. The selectivity of cue responses for associated outcome types, which was represented by $n f r(R)-n f r(N R)$, was much larger in the first part of the trial than in the second part $(p<0.00001, p<0.00001$ in Monkey 1 and $p=0.018$ in Monkey 2, two-tailed Wilcoxon signed rank test). However, for the $28 \mathrm{PRh}$ cells that showed numerically smaller cue responses after reward-associated cues, $n f r(R)-n f r(N R)$ was not significantly different between the first and second parts of the trial $(p=0.49, p=0.68$ in Monkey 1 and $p=0.16$ in Monkey 2), although the signed differences in both parts of the trial were significantly smaller than zero $(p=0.00075$ and 0.0013 for the first and second parts, respectively). Thus, the PRh cells with smaller cue responses after rewardassociated cues had a different nature from the PRh cells with larger cue responses after reward-associated cues.

To statistically confirm the dependence of PRh cells' selectivity on the time context, we compared $n f r(R)-n f r(N R)$ between the first and second parts of the trial (referred to as $\operatorname{dnf} r(1)$ and

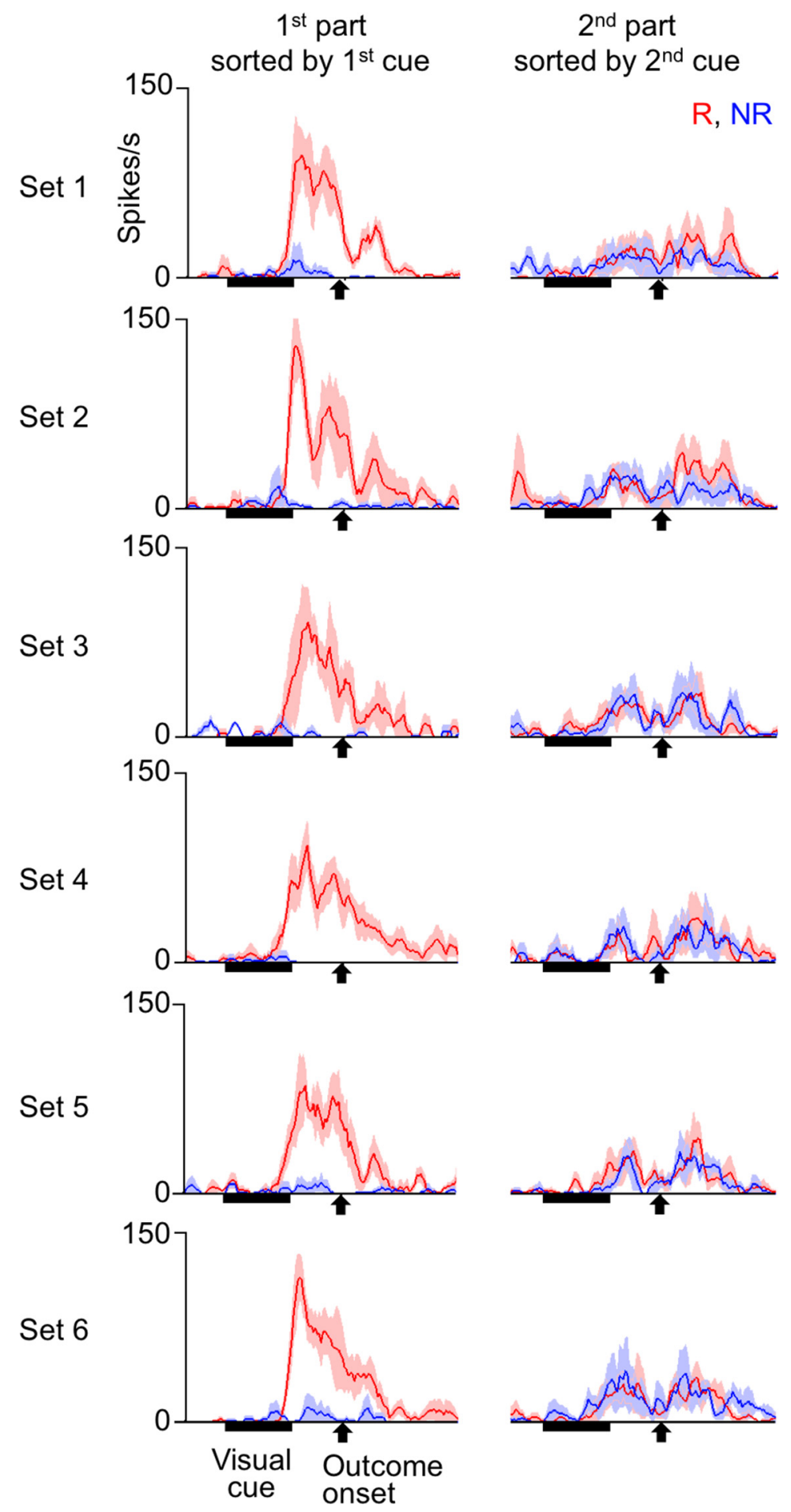

Figure 7. Cue responses of an example PRh cell recorded in the experiments with context-dependent cue-outcome contingency before the first context switch. Trials were sorted by the cue presented in each trial part. Red and blue lines indicate activities in trial parts in which reward-associated and no-reward-associated cues were presented, respectively. The "reward-associated" and "no-reward-associated" categories were defined by the contingency that existed only in the contingent part of the trial. Activities were averaged over trial parts with stimuli belonging to the same stimulus set and associated with the same outcome type. Shading represents SEM across trials. The bin width was $10 \mathrm{~ms}$, and values were smoothened over five bins with equal weights. $d n f r(2)$, respectively) over the cell population. All of the 113 cueresponsive PRh cells (61 in Monkey 1 and 52 in Monkey 2) were put into this analysis. As can be seen in Figure $9 A$, values of $d n f r(1)$ were much more shifted from zero to the positive side (black line) than values of $d n f r(2)$ (gray line). A Wilcoxon signed 
PRh $R>N R$
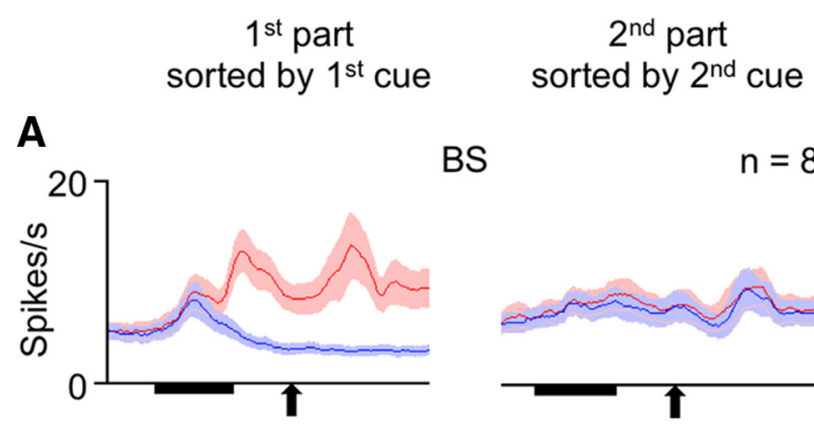

BS $\mathrm{n}=85$

B

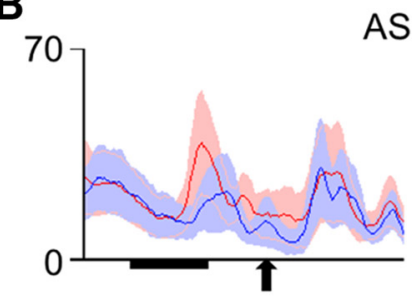

AS (3-12)

$n=6$
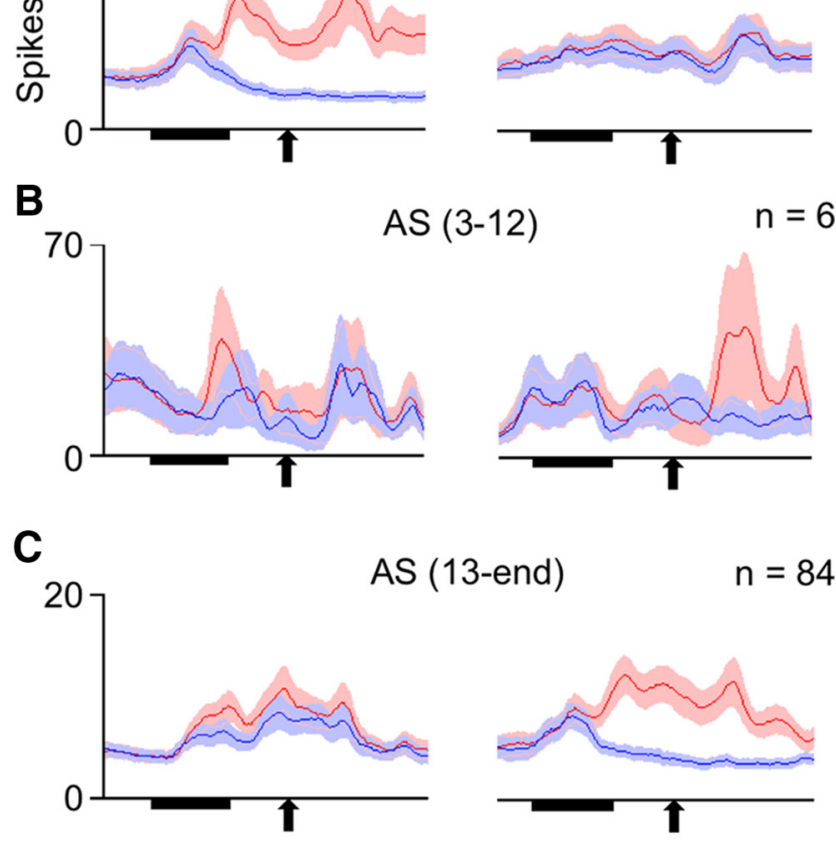

$n=6$

D
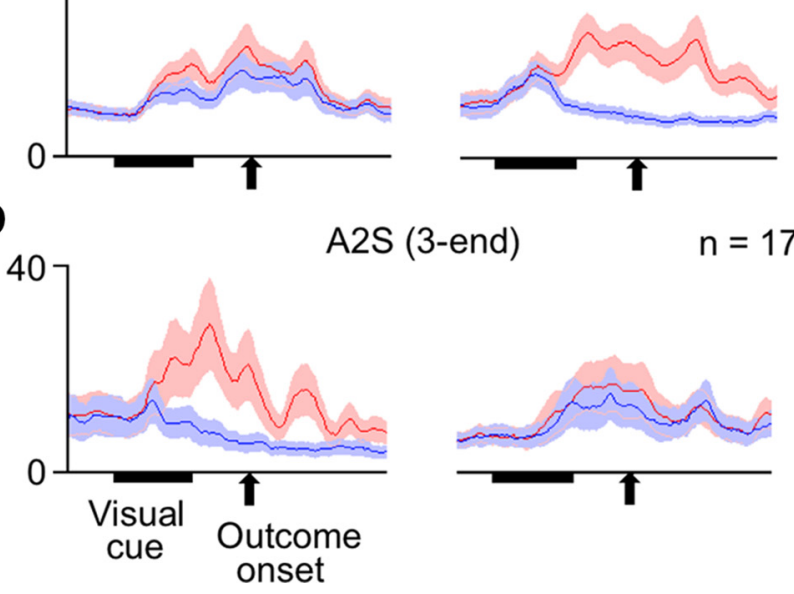

A2S (3-end)

$\mathrm{n}=17$

Figure 8. Mean activities of cue-responsive PRh cells that showed numerically larger cue responses after reward-associated cues than after no-reward-associated cues (in responses averaged between the first and second parts of the trial). Left graphs, Activities in the first part of the trial sorted by the first cue. Right graphs, Activities in the second part of the trial sorted by the second cue. Red and blue lines indicate activities after reward-associated and no-rewardassociated cues, respectively. The "reward-associated" and "no-reward-associated" categories were defined by the contingency that existed only in the contingent part of the trial. $A$, For the cells recorded before the first context switch (BS). $B$, For the cells recorded between the third and 12th days after the first context switch: AS (3-12). C, For the cells recorded between the 13th day after the first context switch and the last day before the second context switch: AS (13-end). $D$, For the cells recorded on the third and later days after the second contest switch: A2S (3-end). $A-D$, Bin width was $10 \mathrm{~ms}$, and values were smoothened over five bins with equal weights. Shading represents SEM across cells.

rank test applied to 113 pairs of $d n f r(1)$ and $d n f r(2)$ indicated that $d n f r(1)$ was significantly larger than $\operatorname{dnfr}(2)(p<0.00001, p<$ 0.00001 in Monkey 1 but $p=0.072$ in Monkey 2, two-tailed Wilcoxon signed rank test). The difference between the first and second parts of a trial appeared only in the positive (i.e., $n f r(R)>$ $n f r(N R)$ ), part of the cumulative histogram (Fig. 9A), corresponding to the absence of time-context dependence in the PRh cells with smaller activities after reward-associated cues.
The dependence of individual cells' selectivities on time context can be quantitatively examined by an interaction in a threeway ANOVA with the associated outcome type (reward, R vs no reward, NR), the time context (contingent vs noncontingent), and stimulus as factors. Of the 113 cue-responsive PRh cells, 36 cells (31 in Monkey 1 and 5 in Monkey 2) showed a significant interaction between the associated outcome type and time context or a significant three-way interaction ( $p<0.025$ each). The $\mathrm{R} / \mathrm{NR}$ differences were larger in the first part of the trial in almost all cells (35 of 36, 31 of 31 in Monkey 1 and 4 of 5 in Monkey 2), and activities that occurred after reward-associated cues were larger than those after no-reward-associated cues in most cells (33 of 36, 29 of 31 in Monkey 1 and 4 of 5 in Monkey 2).

These results on both cell population and individual cells indicated that the selectivity of PRh cells' cue responses for associated outcome types was largely specific to the first part of the trial, in which the monkeys had experienced a constant cue-outcome contingency.

\section{TE cell activities}

There was no significant difference between the first and second parts of the trial in the selectivity of cue responses for associated outcome types in TE cells. Of 120 cue-responsive TE cells (71 in Monkey 1 and 49 in Monkey 2) (213 cells were recorded during the period), 56 and 64 cells ( 32 and 39 in Monkey 1, 24 and 25 in Monkey 2) showed numerically larger and smaller activities after reward-associated cues than after no-reward-associated cues, respectively, for mean activities averaged between the first and second parts of the trial. Activities of an example of the 64 cells are shown in Figure 10, and averaged activities of these two groups of cells are shown in Figure 11A. The selectivity of cue responses for associated outcome types did not differ between the first and second parts of the trial for either group. A Wilcoxon signed rank test applied to the 56 and 64 pairs of $d f r(1)$ and $d f r(2)$ both showed no significant difference $(p=0.58, p=0.56$ in Monkey 1 and $p=0.82$ in Monkey 2, for the cells with numerically larger activities after reward-associated cues; $p=0.69, p=0.21$ in Monkey 1 and $p=0.51$ in Monkey 2, for the cells with numerically smaller activities after reward-associated cues, two-tailed).

At the individual cell level, three-way ANOVA with the associated outcome type, time context, and stimulus as factors detected either a significant main effect of associated outcome type $(p<0.025)$ without a significant interaction between the associated outcome type and stimulus $(p>0.05)$ or a significant interaction between the associated outcome type and stimulus $(p<$ $0.025)$ without a significant three-way interaction $(p>0.05)$ in 56 of the 120 cue-responsive TE cells (19 of 71 in Monkey 1 and 37 of 49 in Monkey 2). This ANOVA pattern means that the cells showed consistent R/NR differences in the first and second parts of the trial. Activities after reward-associated cues were larger and smaller in 20 and 36 cells (12 and 7 in Monkey 1, 8 and 29 in Monkey 2), respectively, than those after no-rewardassociated cues. Significant interactions between the associated outcome type and time context or significant three-way interactions ( $p<0.025$ each) were found in only 10 of the 120 cells ( 2 of 71 in Monkey 1 and 8 of 49 in Monkey 2). This proportion is not significantly larger than those expected by chance $(p=0.13, p=0.27$ in Monkey 1 and $p=0.14$ in Monkey 2, Poisson test).

These results on both cell population and individual cells indicated that the selectivity of TE cells' cue responses for associated outcome types was independent from the time context of the cue-outcome contingency. 


\section{Context switches}

Given that the selectivity of PRh cells' cue responses for associated outcome types was largely specific to the first part of the trial in which the monkeys had consistently experienced the cue-outcome contingency, we moved the cue-outcome contingency to the second part of each trial to examine how fast this context dependence of $\mathrm{PRh}$ cells follows changes in the context. After the context switch, there was now fixed cue-outcome contingency in the second part of the trial, whereas one of two outcome types was randomly provided in the first part of the trial. Furthermore, after cells were recorded for $100 \mathrm{~d}$ (in Monkey 1) or $85 \mathrm{~d}$ (in Monkey 2) in this new task arrangement, we moved the cue-outcome contingency back to the first part of each trial and recorded cells for $18 \mathrm{~d}$ (in Monkey 1) or $12 \mathrm{~d}$ (in Monkey 2). We will refer to these changes in task as the first and second context switches.

\section{Monkeys' behavior}

Both monkeys quickly changed their behavior after the first context switch. In Monkey 1, the R/NR difference in success rate in the second part of the trial, $d s r(2)$, became larger than that in the first part of the trial, $d s r(1)$, from the first day after the switch (Fig. 6B) and continued to be so for 11 consecutive days. Although the difference between $d s r(1)$ and $d s r(2)$ for each day (see Materials and Methods) did not necessarily reach a significance level during those days, a paired $t$ test applied to daily calculated differences in the first $5 \mathrm{~d}$ showed a significant difference $(p=$ 0.0012 , one-tailed). In most of the 5 consecutive-day windows in the period between the first and second context switches, $d s r(2)$ was significantly larger than $d s r(1)$ as well ( 82 of $96, p<0.05$, one-tailed paired $t$ test).

After the second context switch, Monkey 1 started to show a larger R/NR difference in success rate in the first part of the trial than in the second part of the trial from the fifth day after the switch (Fig. 6B) and continued to do so for the remaining $14 \mathrm{~d}$ until the end of recordings. All sets of 5 consecutive days during this period (fifth to 18th days) showed significantly larger differences in the first part of the trial $(p<0.05$, one-tailed paired $t$ test).

In Monkey 2, the R/NR difference in anticipatory sucking pressure in the second part of the trial, $d s p(2)$, became larger than that in the first part of the trial, $d s p(1)$, from the third day after the first context switch (Fig. 6C) and continued to be so for $37 \mathrm{~d}$. A paired $t$ test applied to daily calculated $d s p(1)$ and $d s p(2)$ in the third to seventh days showed a significant difference $(p=0.0056$, one-tailed), and $d s p(2)$ was significantly larger than $d s p(1)$ in most sets of 5 consecutive days during the period between the third and 63rd days after the first context switch (52 of 57, $p<$ 0.05 , one-tailed paired $t$ test). After the $63 \mathrm{rd}$ day until the last day
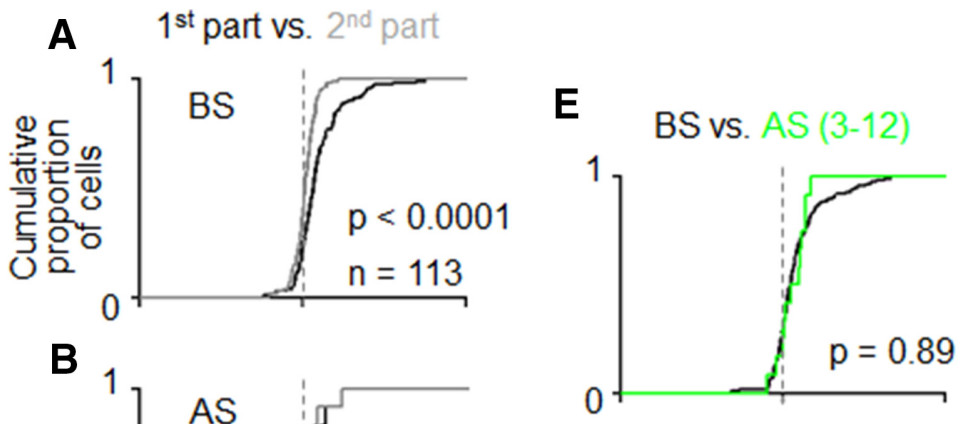

F
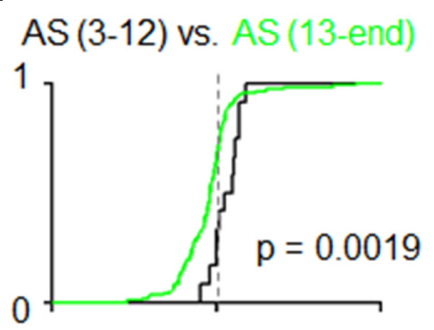

\section{G}
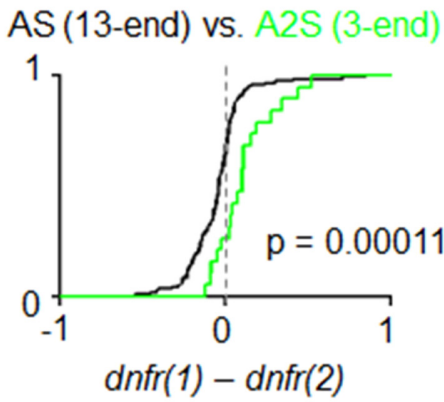

Figure 9. Quantitative comparison of the selectivity of cue responses for associated outcome types between the contingent and noncontingent parts of the trial. $\boldsymbol{A}$, Cumulative proportions of cells plotted against $n f r(R)-n f r(N R)$ : the normalized cue responses after reward-associated cues subtracted by those after no-reward associated cues, in the first and second parts of the trial (black and between the third and 12th days after the first context switch: AS (3-12). $\boldsymbol{C}$, The same as in $\boldsymbol{A}, \boldsymbol{B}$ but for the cells recorded between 列 that in the second part of the trial, in BS (black line) and AS (3-12) (green line). $\boldsymbol{F}$, The same as in $\boldsymbol{E}$ but for AS (3-12) (black line) and AS (13-end) (green line). $\boldsymbol{G}$, The same as in $\boldsymbol{E}, \boldsymbol{F}$ but for AS (13-end) (black line) and A2S (green line).

before the second context switch (the 85th day after the first context switch), the differences in anticipatory sucking were small in both the first and second parts of the trial. However, in many of these $23 \mathrm{~d}$, the difference in success rate showed clear differences between the first and second parts of the trial (Fig. $6 D)$. A paired $t$ test applied to success rate differences during 5 consecutive-day windows in this period showed significantly larger differences in the second part than in the first part of the trial $(p<0.05)$ in a majority of 5 day windows (11 of 19).

After the second context switch, Monkey 2 started to show a larger difference in anticipatory sucking pressure in the first part of the trial than in the second part from the third day after the switch (Fig. 6C) and continued to do so for $10 \mathrm{~d}$ until the end of recordings. $d s p(1)$ was significantly larger than $d s p(2)$ in all of 5 consecutive-day windows during this period ( $p<0.05$, onetailed paired $t$ test). 

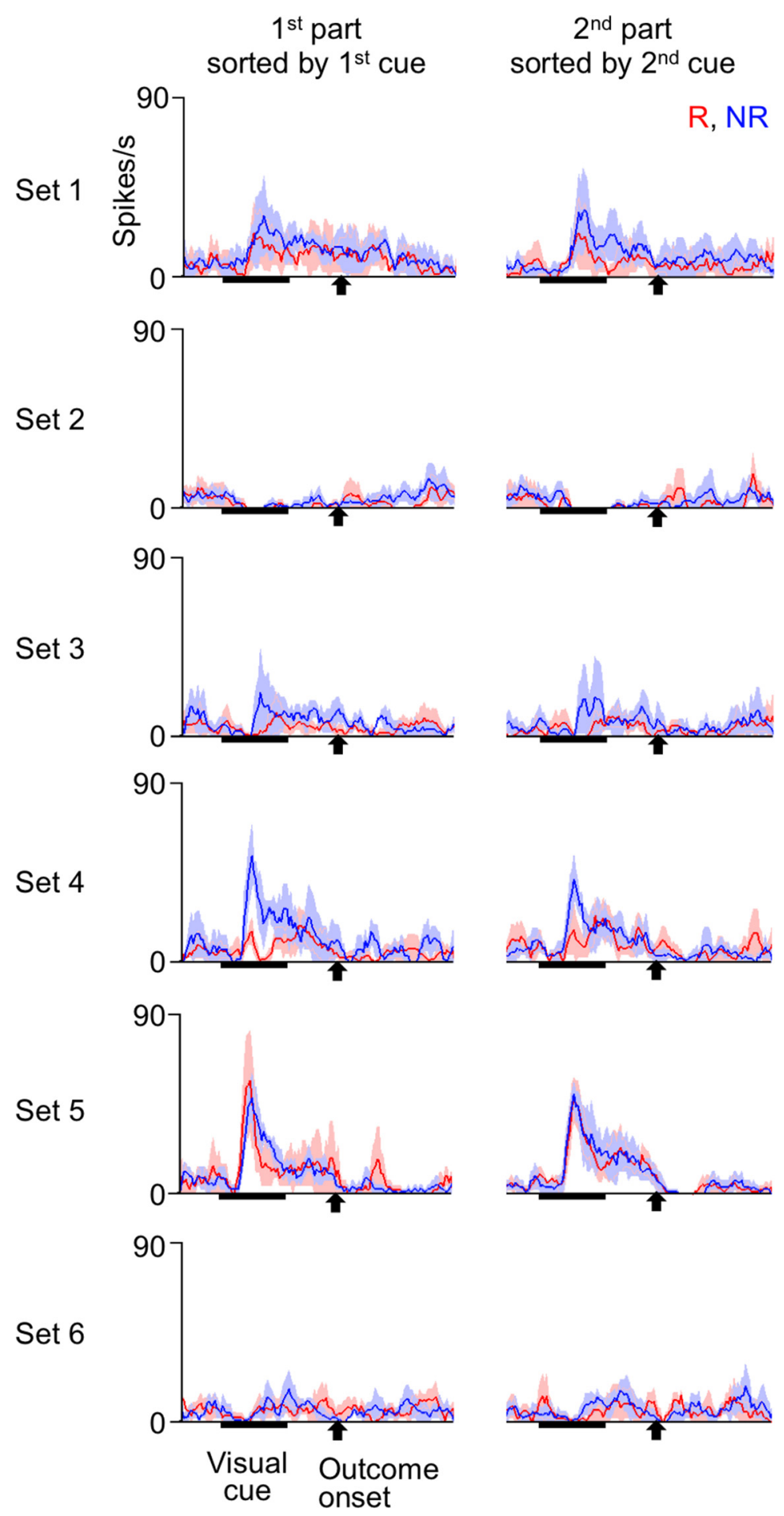

Figure 10. Cue responses of an example TE cell recorded in the experiments with context-dependent cue-outcome contingency before the first context switch. The formats are identical to those in Figure 7.

The adaptation of the monkeys' anticipatory behavior to the new time context after the first context switch was incomplete, although strong. In Monkey 1 , although $d s r(1)$ was significantly smaller than $d \operatorname{sr}(2)(p<0.00001$, two-tailed Wilcoxon signed rank test), $s r(R)$ in the first part of the trial was larger than $s r(N R)$ in that part of the trial during most of the $100 \mathrm{~d}$ between the first and second context switches. Comparison between $\operatorname{sr}(R)$ and $s r(N R)$ in the first part of the trial over the $100 \mathrm{~d}$ showed a highly significant difference $(p<0.00001$, two-tailed Wilcoxon signed rank test). In Monkey 2, although $d s p(1)$ was significantly smaller than $d s p(2)$, $s p(R)$ in the first part of the trial was larger than $s p(N R)$ in that part of the trial in most of the $85 \mathrm{~d}$ between the first and second context switches. Comparison between $s p(R)$ and $s p(N R)$ in the first part of the trial over the $85 \mathrm{~d}$ showed a highly significant difference $(p<0.00001$, twotailed Wilcoxon signed rank test).

\section{PRh cell activities}

The selectivity of PRh cells' cue responses for associated outcome types moved to the second part of the trial after the first context switch, but with a delay of $\sim 13 \mathrm{~d}$.

Over a period from the 13th day after the first context switch to the last day before the second context switch, the selectivity of PRh cells' cue responses for associated outcome types was mostly limited to the second part of the trial (Fig. $8 C)$. The distribution of $\mathrm{R} / \mathrm{NR}$ differences in the second part of the trial, $\operatorname{dnfr}(2)$, was much more shifted from zero to the positive side (gray line) than that of R/NR differences calculated for activities in the first part, $d n f r(1)$ (black line) (Fig. 9C): $d n f r(2)$ was significantly larger than $d n f r(1)(p=$ $0.000016, p=0.00092$ in Monkey 1 and $p=0.018$ in Monkey 2, two-tailed Wilcoxon signed rank test). However, the cells recorded between the third and 12th days after the first context switch showed a pattern more similar to those recorded before the first context switch than to those recorded on later days after the first context switch (Figs. $8 B$ and $9 B$ ): $d n f r(1)$ was significantly larger than $d n f r(2)$ in 12 $\mathrm{PRh}$ cells recorded between the third and 12th days after the first context switch ( $p=0.034$, two-tailed Wilcoxon signed rank test). When the difference between the first and second parts of the trial, $d n f r(1)-d n f r(2)$, was compared among the three recording periods, $d n f r(1)-$ $d n f r(2)$ for third to 12 th days after the first context switch was not significantly different from that before the first context switch $(p=0.89$, two-tailed Wilcoxon signed rank test; Fig. 9E), whereas it was significantly larger than that on the later days after the first context switch $(p=$ 0.0019; Fig. 9F).

After the second context switch, however, the selectivity of PRh cells' cue responses for associated outcome types quickly moved back to the first part (Fig. 8D). In the 19 cue-responsive cells recorded during a period of 12 (in Monkey 1) or $18 \mathrm{~d}$ (in Monkey 2) after the second context switch, $d n f r(1)$ was significantly larger than $\operatorname{dnfr}(2)$ ( $p=0.016$, two-tailed Wilcoxon signed rank test) (Fig. 9D), and $d n f r(1)-d n f r(2)$ for this period of recordings was significantly larger than that in the period between the 13th day after the first context switch and the last day before the second 


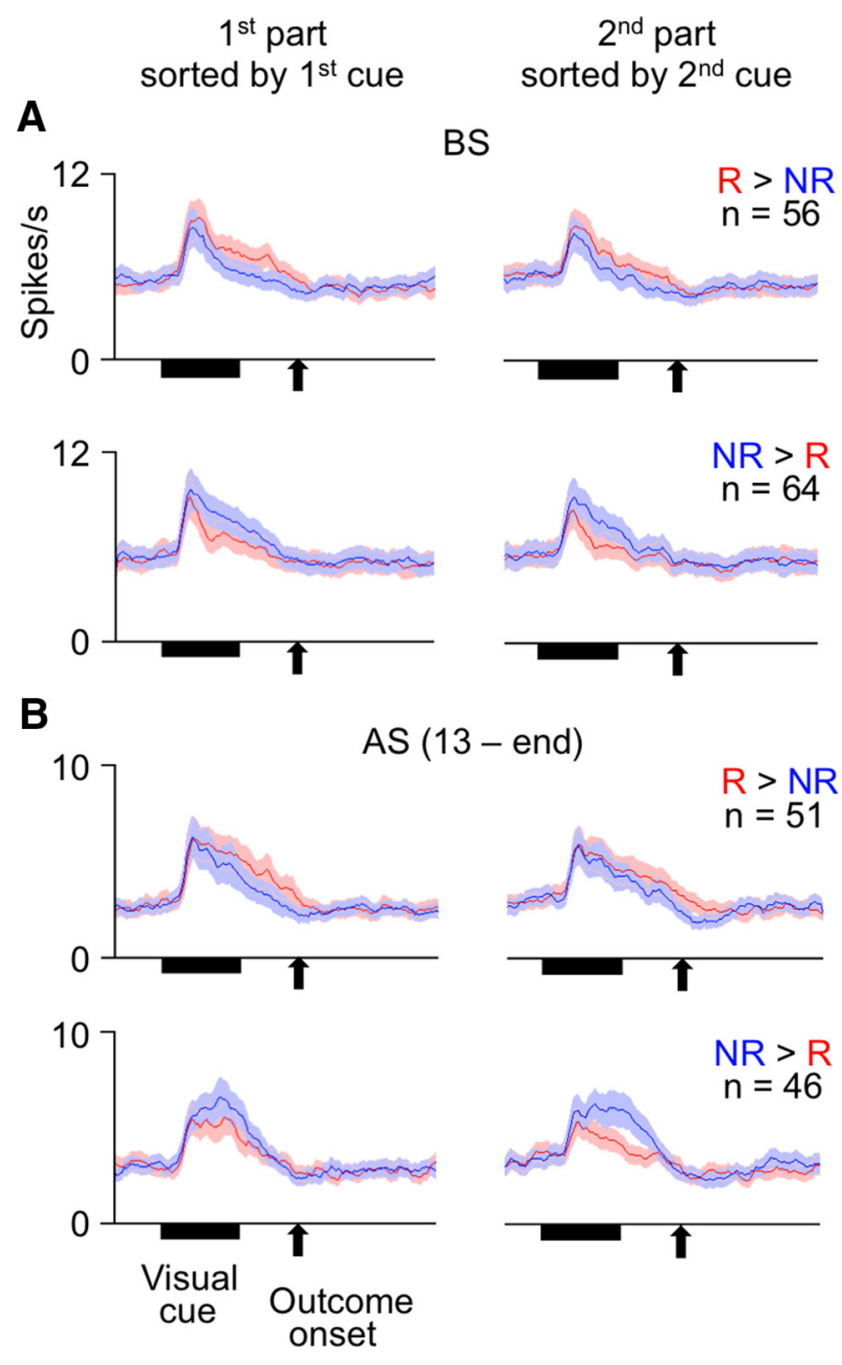

Figure 11. Mean activities of cue-responsive TE cells. Left graphs, Activities in the first part of the trial sorted by the first cue. Right graphs, Activities in the second part of the trial sorted by the second cue. The cells were divided into two groups that showed numerically larger and smaller cue responses after reward-associated cues than after no-reward-associated cues (in responses averaged between the first and second parts of the trial). Red and blue lines indicate activities after reward-associated and no-reward associated cues, respectively. Bin width was $10 \mathrm{~ms}$, and values were smoothed over five bins with equal weights. Shading represents SEM across cells. $\boldsymbol{A}$, For the cells recorded before the first context switch (BS). $\boldsymbol{B}$, For the cells recorded between the 13th day after the first context switch and the last day before the second context switch: AS (13 - end).

context switch ( $p=0.00011$, two-tailed Wilcoxon signed rank test) (Fig. $9 G$ ). Similar conclusions were obtained even for 17 cells recorded during the first $10 \mathrm{~d}$ after the second context switch ( $p=0.0034$ for the differences between $d n f r(1)$ and $d n f r(2) ; p=0.000048$ for the differences in $d n f r(1)-d n f r(2)$ from those cells recorded between the 13th day after the first context switch and the last day before the second context switch).

\section{TE cell activities}

Consistent with the observation that selectivity of TE cells' cue responses for associated outcome types did not differ between the first and second parts of the trial before the first context switch, there was no significant difference between $d n f r(1)$ and $d n f r(2)$ in 97 cue-responsive TE cells recorded in the period from the 13th day after the first context switch to the last day before the second context switch (Fig. 11B). Of the 97 cue-responsive TE cells (46 in
Monkey 1 and 51 in Monkey 2), 51 and 46 cells (20 and 26 in Monkey 1, 31 and 20 in Monkey 2) showed numerically larger and smaller activities after reward-associated cues than after noreward-associated cues, respectively. $d n f r(1)$ was not significantly different from $d n f r(2)$ in either group of cells ( $p=0.23, p=0.079$ in Monkey 1 and $p=0.83$ in Monkey 2, for the cells with numerically larger activities after reward-associated cues; and $p=0.10$, $p=0.052$ in Monkey 1 and $p=0.68$ in Monkey 2, for the cells with numerically smaller activities after reward-associated cues, two tailed Wilcoxon signed rank test).

\section{Cell activities after the outcome onset}

Many PRh cells continued to show differential activities selective for outcome type (water reward or sound only) after the outcome onset. The experiments in which the cue-outcome sequence was repeated twice in each trial provided a good opportunity to examine the nature of these differential activities after the outcome onset.

\section{PRh cell activities}

We first examined activities after the outcome onset in the noncontingent part of each trial to determine whether the cells differentially responded to the occurrence of two types of outcome even when there was no systematic cue-outcome contingency. Of the $217 \mathrm{PRh}$ cells (109 in Monkey 1 and 108 in Monkey 2) recorded before the first context switch, 48 and 25 cells ( 37 and 7 in Monkey 1 and 11 and 18 in Monkey 2) showed significantly larger and smaller activities, respectively, after the water delivery than after the sound-only acknowledgment (in the $500 \mathrm{~ms}$ window starting at $200 \mathrm{~ms}$ after the electrical onset of outcome, $p<0.05$, two-tailed Wilcoxon signed rank test) in the second (noncontingent) part of the trial (Fig. 12A, left). Of the $278 \mathrm{PRh}$ cells ( 100 in Monkey 1, 178 in Monkey 2) recorded during the period from the 13th day after the first context switch to the last day before the second context switch, 57 and 9 cells (44 and 5 in Monkey 1, 13 and 4 in Monkey 2) showed significantly larger and smaller activities, respectively, after the water delivery than after the soundonly acknowledgment in the first (noncontingent) part of the trial (Fig. 12A, right). Because there was no cue-outcome contingency in the second part of the trial before the first context switch and in the first part of the trial between the first and second context switches, these differential activities in PRh cells appear to have been evoked by the actual delivery of the outcomes.

Many of the PRh cells that showed significantly larger outcome responses to the water delivery than the sound-only acknowledgment in the noncontingent part of trial also showed significantly larger cue responses after reward-associated cues than after no-reward-associated cues in the contingent part of the trial (67 of 105 cells: 56 of 81 in Monkey 1 and 11 of 24 in Monkey $2, p<0.05$, two-tailed Wilcoxon signed rank test). The outcome responses of these 67 cells in the noncontingent part of the trial might have represented errors in reward prediction (Schultz et al., 1997). However, most of them (61 of 67: 55 of 56 in Monkey 1 and 6 of 11 in Monkey 2) also showed significantly larger outcome responses to the water delivery than the sound-only acknowledgment in the contingent part of the trial $(p<0.05$, two-tailed Wilcoxon signed rank test). Moreover, the differences between outcome responses after the water delivery and soundonly acknowledgment, in the 67 cells, were significantly larger or comparable in the contingent part of the trial compared with those in the noncontingent part of the trial $(p=0.0010, p=$ 0.00011 in Monkey 1 and $p=0.46$ in Monkey 2, two-tailed Wil- 
A $\quad$ BS $\quad R>N R$

\section{Selected by responses} to $2^{\text {nd }}$ outcome $n=48$
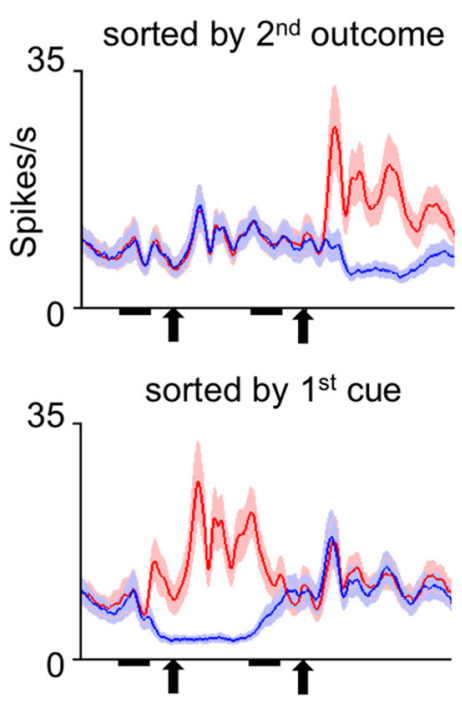

AS (13-end) $R>N R$

\section{Selected by responses}

to $1^{\text {st }}$ outcome
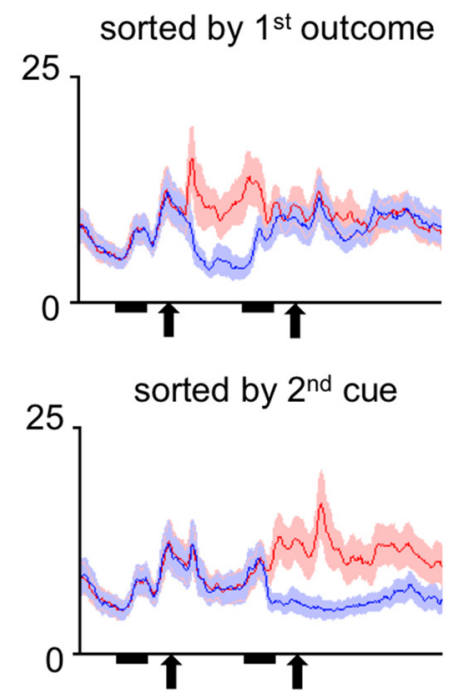

B

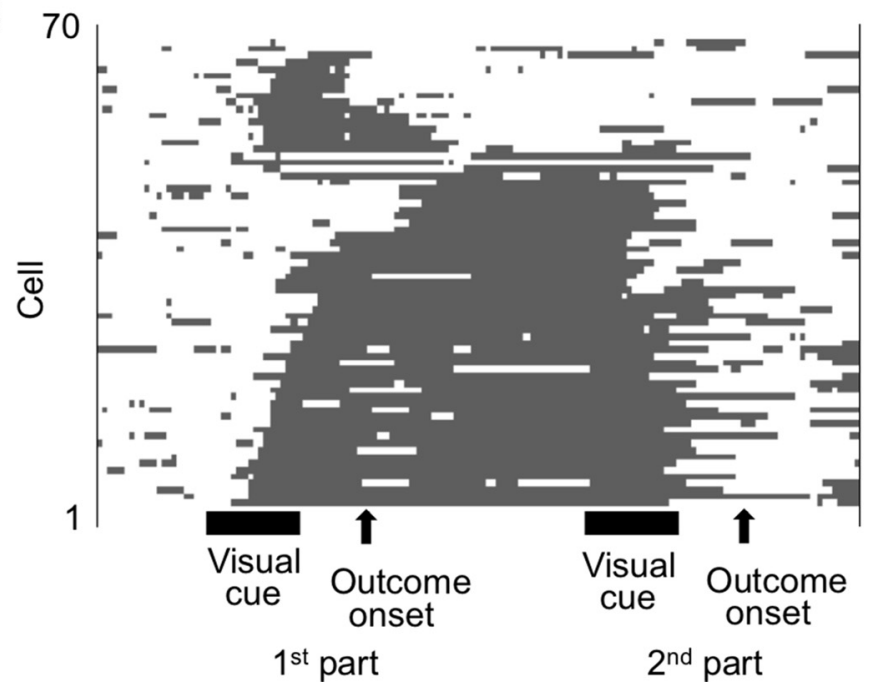

Figure 12. Responses of PRh cells to reward delivery. $A$, Mean activities of PRh cells selected by significantly larger responses to water delivery than to sound-only acknowledgment in the noncontingent part of the trial. Left graphs, Activities of cells recorded before the first context switch (BS). Right graphs, Activities of cells recorded between the 13th day after the first context switch and the last day before the second context switch: AS ( 13 - end). Trials were sorted by actual outcome types in the noncontingent part of trial in the top graphs and by cues in the contingent part of trial in the bottom graphs. Bin width was $10 \mathrm{~ms}$, and values were smoothened over five bins with equal weights. Shading represents SEM across cells. $\boldsymbol{B}$, Periods during which each cell showed significantly larger activities in response to the presentation of reward-associated cues and the delivery of water rewards. The analysis was applied to activities in the first (contingent) part of trial. The $70 \mathrm{PRh}$ cells included in the analysis were recorded during the BS period and selected for significantly larger cue responses after reward-associated cues or significantly larger outcome responses to the water reward in the first part of trial. A line indicates a cell. Gray parts in each line represent the periods in which the cell showed significant differences in a $200 \mathrm{~ms}$ window moving with $20 \mathrm{~ms}$ steps. The cells were aligned from the bottom to the top according to the length of persistent significant differences.

coxon signed rank test). Therefore, these activities of the PRh cells could not reflect errors in reward prediction.

In the contingent part of the trial, many PRh cells maintained differential activities selective for outcome types from some time after the cue onset through the outcome delivery until the perception of the next cue (Fig. 12B). Before the first context switch, 70 PRh cells (56 in Monkey 1 and 14 in Monkey 2) showed significantly larger activities after reward-associated cues in $n=57$

the cue-response window or after water reward delivery in the outcome-response window (500 ms starting at $200 \mathrm{~ms}$ after the outcome onset) ( $p<0.025$ each, twotailed Mann-Whitney $U$ test) in the first part of the trial. When the statistical significance of the differential activity was examined in these cells with a $200 \mathrm{~ms}$ window moving at $20 \mathrm{~ms}$ steps (see Materials and Methods), the duration of the period (determined by the center of window) in which the cell consistently showed significantly larger activities in response to reward-associated cues and water reward delivery was $1091 \pm 56 \mathrm{~ms}$ (mean \pm SEM across cells; $1192 \pm 52 \mathrm{~ms}$ in Monkey 1 and $688 \pm 143 \mathrm{~ms}$ in Monkey 2). More than a half of the cells ( 42 of 70: 38 of 56 in Monkey 1 and 4 of 14 in Monkey 2) showed persistent significant differences for a period longer than $1000 \mathrm{~ms}$.

\section{TE cell activities}

TE cells did not show outcome-dependent activities after outcome onset in the noncontingent part of the trial. Of the $213 \mathrm{TE}$ cells (147 in Monkey 1 and 66 in Monkey 2) recorded before the first context switch, only 10 cells ( 6 in Monkey 1 and 4 in Monkey 2) showed significant outcome responses in the second (noncontingent) part of the trial (in the $500 \mathrm{~ms}$ window starting at $200 \mathrm{~ms}$ after the electrical onset of outcome, $p<0.05$, two-tailed Wilcoxon signed rank test). Of the $171 \mathrm{TE}$ cells (101 in Monkey 1 and 70 in Monkey 2) recorded during the period from the 13th day after the first context switch to the last day before the second context switch, only 14 cells ( 10 in Monkey 1 and 4 in Monkey 2) showed significant outcome responses in the first (noncontingent) part of the trial. The proportions of 10 of 213 and 14 of 171 were not significantly larger than those expected by chance $(p=$ 0.13 and $p=0.11$, respectively, Poisson test). Thus, TE cells did not respond differentially to reward and no reward when there was no consistent cueoutcome contingency.

\section{Discussion}

We found that PRh cells represented, in their responses to visual cues, the outcome type (water reward or sound only) contingent to the cue (Fig. 4) and that this representation appeared only in the trial part in which the monkeys had experienced the stimulus-outcome contingency (Figs. 7, 8 , and 9). Thus, PRh cells not only represented the stimulusoutcome contingency but also represented the time context in which the contingency had existed. PRh is not specific to the representation of sensory and associative properties of objects themselves (Eichenbaum et al., 2007; Ranganath and Ritchey, 
2012) but may represent broader information about objects, including the time context in which the objects are associated with particular outcomes.

This time-context-dependent representation of stimulusoutcome contingency in PRh cells was not a mere reflection of the monkey's expectation of particular outcomes or the consequent changes in motivation level. We found clear dissociations between the monkey's behavior and PRh cell activities in two situations. First, when the monkeys had experienced a sequence of no visual stimulus and water reward, the monkeys showed a full anticipation of the reward (Fig. 3), whereas activities of PRh cells were not significantly different from their baseline activities (Fig. 5). Second, after the first context switch in the second series of experiments, the monkeys started to show stronger expectation of outcome types in the newly contingent part of the trial than in the previously contingent part of the trial within $3 \mathrm{~d}$ (Fig. 6), whereas PRh cell activities started to adapt to the context switch after another $10 \mathrm{~d}$ delay (Figs. 8 and 9). The first dissociation also indicated that the representation of associated outcome in PRh was conditional to the existence of complex visual feature inputs. PRh cells may be located in the middle of the translation of visual inputs to the associated outcome types, and not just representing outputs of the translation. The second dissociation suggested that the representation of stimulus-outcome contingency in PRh cells reflected the long-term experience of the contingency for the past 10 days or longer.

PRh has appropriate anatomical connections for the representation of stimulus-outcome contingency in a particular time context. It receives information about visual properties of objects from TE (Webster et al., 1991; Suzuki and Amaral, 1994; Saleem and Tanaka, 1996). It may receive information of reward by the projections from dopamine cells in the ventral tegmental area and those from the amygdala and orbitofrontal cortex (Goldsmith and Joyce, 1996; Stefanacci et al., 1996; Kondo et al., 2005). Information about the time context may originate in the hippocampus. Cells in CA1 of the hippocampus map time points in repeated task sequences (Eichenbaum, 2013). The information of time mapping may propagate from CA1 to PRh directly or via the entorhinal cortex. It has been found that PRh cells represented the time of presentation as well as identity of visual stimuli when their time sequences were encoded into short-term memory (Naya and Suzuki, 2011). The time-context information may also originate in the lateral prefrontal cortex, which contains many cells representing the task structure, including its temporal aspects (Miller and Cohen, 2001; Tanji and Hoshi, 2008; Saga et al., 2011). The requirement of complex visual feature inputs, relatively slow changes after the first context switch and dependence on time context suggest that the time-context-dependent representation of stimulus-outcome contingency is an emergent function in PRh. However, the results in the present experiments do not exclude the possibility that the representations first emerged in another brain site (e.g., the amygdala and orbitofrontal cortex) and are sent to PRh.

Associative properties of TE cells contrasted sharply with those of PRh cells in several aspects. First, responses of TE cells continued to be determined primarily by visual properties of the cues even after training (Fig. 4C). Second, the associatedoutcome-dependent components of cue responses in TE cells indiscriminately appeared in both the contingent and noncontingent parts of the trial (Figs. 10 and 11). Therefore, once the system has learned the stimulus-outcome contingency over a long period, the differential responses of TE cells appeared when- ever the stimulus occurred. These results, together, suggest that the differential activities in TE cells represent a categorization embedded into the stimulus selectivity of the cells. The translation from visual features to meanings (reward or no reward in this case) developed much more in PRh.

Neuronal activities correlated with animals' expectation of particular outcomes have been observed in various parts of the brain. Their functions may be diverse. Dopamine cells in the ventral tegmental area and substantia nigra, as well as cells in the anterior cingulate cortex, represent errors in reward prediction (Schultz and Dickinson, 2000; Matsumoto et al., 2007; Quilodran et al., 2008; Kuwabara et al., 2014), which may reinforce the learning of value-based action or rule selection (Schultz et al., 1997). Because PRh cells responded to reward delivery at least as strongly when it was expected in the contingent part of a trial as when it was unexpected in the noncontingent part of a trial, their activities do not simply represent reward prediction errors. The differential activities of PRh cells in the contingent part of a trial started after the cue presentation and continued through the outcome delivery until the perception of a new cue in the next trial part (Fig. 12B). These continuing activities may work, not for the simple reinforcement learning of behavioral responses, but as the bases to form an inclusive association incorporating events consistently occurring in the vicinity of the outcome with events already associated with it. Such continuing activities could be advantageous for forming inclusive associations.

There has been plenty of evidence that PRh cells represent associations between visual stimuli (Miyashita and Chang, 1988; Sakai and Miyashita, 1991; Higuchi and Miyashita, 1996; Erickson and Desimone, 1999) as well as associations between visual stimuli and reward-related information (Liu and Richmond, 2000; Mogami and Tanaka, 2006; Ohyama et al., 2012). Information about the context in which those associations will likely occur is as important as that of the associations themselves for guiding animals' behavior. We here propose that various types of information related to objects, including the time context in which stimulus-outcome contingencies occur, are represented by PRh cell activities. This integration of time context with stimulusoutcome contingencies occurred slowly along many repetitions of the experience over more than a week (Figs. $8 B, C$ and $9 B, C, E, F)$. The previous findings of associative representations of object features in PRh were also based on observations after the animals had experienced the contingency many times. Such slow learning that requires many repetitions may be a common characteristic of association representations in PRh cells, which are advantageous to extract regularities existing over multiple events. However, we found that, when a previously learned time context of stimulus-outcome contingency was reexperienced, the representation of the time context in PRh cells quickly recovered (Figs. $8 D$ and $9 D, G)$. Thus, once an association in a context is consolidated, and after its apparent extinction under a different context, it may quickly appear again when the context returns to the original. This flexible switching between consolidated association memories is advantageous for animals experiencing alternations between multiple but repeating environmental constraints.

In conclusion, we found that associations represented by $\mathrm{PRh}$ cells are highly inclusive in nature, encoding regularities in past experiences to form representations that are stable but adaptable to repeating regularities. In contrast, association memories represented by TE cells are less inclusive and probably related primarily to their selectivity for visual features. The stable, inclusive 
associations represented by PRh cells may form a core part of animal's semantic knowledge about the environment.

\section{References}

Buckley MJ, Gaffan D (1998) Perirhinal cortex ablation impairs configural learning and paired-associate learning equally. Neuropsychologia 36: 535-546. CrossRef Medline

Chan AM, Baker JM, Eskandar E, Schomer D, Ulbert I, Marinkovic K, Cash SS, Halgren E (2011) First-pass selectivity for semantic categories in human anteroventral temporal lobe. J Neurosci 31:18119-18129. CrossRef Medline

Davachi L (2006) Item, context and relational episodic encoding in humans. Curr Opin Neurobiol 16:693-700. CrossRef Medline

Davies RR, Graham KS, Xuereb JH, Williams GB, Hodges JR (2004) The human perirhinal cortex and semantic memory. Eur J Neurosci 20:24412446. CrossRef Medline

Eichenbaum H (2013) Memory of time. Trends Cogn Sci 17:81-88. CrossRef Medline

Eichenbaum H, Yonelinas AP, Ranganath C (2007) The medial temporal lobe and recognition memory. Annu Rev Neurosci 30:123-152. CrossRef Medline

Erickson CA, Desimone R (1999) Responses of macaque perirhinal neurons during and after visual stimulus association learning. J Neurosci 19: 10404-10416. Medline

Goldsmith SK, Joyce JN (1996) Dopamine D2 receptors are organized in bands in normal human temporal cortex. Neuroscience 74:435-451. CrossRef Medline

Goulet S, Murray EA (2001) Neural substrates of crossmodal association memory in monkeys: the amygdala versus the anterior rhinal cortex. Behav Neurosci 115:271-284. CrossRef Medline

Hammond LJ (1980) The effect of contingency upon the appetitive conditioning of free-operant behavior. J Exp Anal Behav 34:297-304. CrossRef Medline

Higuchi S, Miyashita Y (1996) Formation of mnemonic neuronal responses to visual paired associates in inferotemporal cortex is impaired by perirhinal and entorhinal lesions. Proc Natl Acad Sci U S A 93:739-743. CrossRef Medline

Holdstock JS, Hocking J, Notley P, Devlin JT, Price CJ (2009) Integrating visual and tactile information in the perirhinal cortex. Cereb Cortex 19: 2993-3000. CrossRef Medline

Kondo H, Saleem KS, Price JL (2005) Differential connections of the perirhinal and parahippocampal cortex with the orbital and medial prefrontal networks in macaque monkeys. J Comp Neurol 493:479-509. CrossRef Medline

Kuwabara M, Mansouri FA, Buckley MJ, Tanaka K (2014) Cognitive control functions of anterior cingulate cortex in macaque monkeys performing a Wisconsin card sorting test analog. J Neurosci 34:7531-7547. CrossRef Medline

Liu Z, Richmond BJ (2000) Response differences in monkey TE and perirhinal cortex: stimulus association related to reward schedules. J Neurophysiol 83:1677-1692. Medline

Liu Z, Murray EA, Richmond BJ (2000) Learning motivational significance of visual cues for reward schedules requires rhinal cortex. Nat Neurosci 3:1307-1315. CrossRef Medline

Liu Z, Richmond BJ, Murray EA, Saunders RC, Steenrod S, Stubblefield BK, Montague DM, Ginns EI (2004) DNA targeting of rhinal cortex D2 receptor protein reversibly blocks learning of cues that predict reward. Proc Natl Acad Sci U S A 101:12336-12341. CrossRef Medline

Matsumoto M, Matsumoto K, Abe H, Tanaka K (2007) Medial prefrontal cell activity signaling prediction errors of action values. Nat Neurosci 10:647-656. CrossRef Medline

McClelland JL, Rogers TT (2003) The parallel distributed processing approach to semantic cognition. Nat Rev Neurosci 4:310-322. CrossRef Medline

Messinger A, Squire LR, Zola SM, Albright TD (2001) Neural representa- tions of stimulus associations develop in the temporal lobe during learning. Proc Natl Acad Sci U S A 98:12239-12244. CrossRef Medline

Miller EK, Cohen JD (2001) An integrative theory of prefrontal cortex function. Annu Rev Neurosci 24:167-202. CrossRef Medline

Miyashita Y, Chang HS (1988) Neural correlate of pictorial short-term memory in the primate temporal cortex. Nature 331:68-70. CrossRef Medline

Mogami T, Tanaka K (2006) Reward association affects neuronal responses to visual stimuli in macaque TE and perirhinal cortices. J Neurosci 26: 6761-6770. CrossRef Medline

Naya Y, Suzuki WA (2011) Integrating what and when across the primate medial temporal lobe. Science 333:773-776. CrossRef Medline

Ohyama K, Sugase-Miyamoto Y, Matsumoto N, Shidara M, Sato C (2012) Stimulus-related activity during conditional associations in monkey perirhinal cortex neurons depends on upcoming reward outcome. J Neurosci 32:17407-17419. CrossRef Medline

Parker A, Gaffan D (1998) Lesions of the primate rhinal cortex cause deficits in flavor-visual associative memory. Behav Brain Res 93:99-105. CrossRef Medline

Pascalis O, Hunkin NM, Bachevalier J, Mayes AR (2009) Change in background context disrupts performance on visual paired comparison following hippocampal damage. Neuropsychologia 47:2107-2113. CrossRef Medline

Quilodran R, Rothé M, Procyk E (2008) Behavioral shifts and action valuation in the anterior cingulate cortex. Neuron 57:314-325. CrossRef Medline

Ranganath C, Ritchey M (2012) Two cortical systems for memory-guided behavior. Nat Rev Neurosci 13:713-726. CrossRef Medline

Saga Y, Iba M, Tanji J, Hoshi E (2011) Development of multidimensional representations of task phases in the lateral prefrontal cortex. J Neurosci 31:10648-10665. CrossRef Medline

Sakai K, Miyashita Y (1991) Neural organization for the long-term memory of paired associates. Nature 354:152-155. CrossRef Medline

Saleem KS, Tanaka K (1996) Divergent projections from the anterior inferotemporal area TE to the perirhinal and entorhinal cortices in the macaque monkey. J Neurosci 16:4757-4775. Medline

Schultz W, Dickinson A (2000) Neural coding of prediction errors. Annu Rev Neurosci 23:473-500. CrossRef Medline

Schultz W, Dayan P, Montague PR (1997) A neural substrate of prediction and reward. Science 275:1593-1599. CrossRef Medline

Stefanacci L, Suzuki WA, Amaral DG (1996) Organization of connections between the amygdaloid complex and the perirhinal and parahippocampal cortices in macaque monkeys. J Comp Neurol 375:552-582. CrossRef Medline

Suzuki WA, Amaral DG (1994) Perirhinal and parahippocampal cortices of the macaque monkey: cortical afferents. J Comp Neurol 350:497-533. CrossRef Medline

Suzuki WA, Naya Y (2014) The perirhinal cortex. Annu Rev Neurosci 37: 39-53. CrossRef Medline

Tanaka K (1996) Representation of visual features of objects in the inferotemporal cortex. Neural Netw 9:1459-1475. CrossRef Medline

Tanji J, Hoshi E (2008) Role of the lateral prefrontal cortex in executive behavioral control. Physiol Rev 88:37-57. CrossRef Medline

Taylor KI, Moss HE, Stamatakis EA, Tyler LK (2006) Binding crossmodal object features in perirhinal cortex. Proc Natl Acad Sci U S A 103:82398244. CrossRef Medline

Wang G, Obama S, Yamashita W, Sugihara T, Tanaka K (2005) Prior experience of rotation is not required for recognizing objects seen from different angles. Nat Neurosci 8:1768-1775. CrossRef Medline

Wang WC, Lazzara MM, Ranganath C, Knight RT, Yonelinas AP (2010) The medial temporal lobe supports conceptual implicit memory. Neuron 68:835-842. CrossRef Medline

Webster MJ, Ungerleider LG, Bachevalier J (1991) Connections of inferior temporal areas TE and TEO with medial temporal-lobe structures in infant and adult monkeys. J Neurosci 11:1095-1116. Medline

Wise RA (2004) Dopamine, learning and motivation. Nat Rev Neurosci 5:483-494. CrossRef Medline 